\title{
Molecular Mechanism of Holin Transmembrane Domain I in Pore Formation and Bacterial Cell Death
}

Muralikrishna Lella, ${ }^{1}$ Soumya Kamilla, ${ }^{2}$ Vikas Jain ${ }^{2}{ }^{*}$ and Radhakrishnan Mahalakshmi ${ }^{1} *$

${ }^{1}$ Molecular Biophysics Laboratory, Department of Biological Sciences, Indian Institute of Science

Education and Research, Bhopal, India-462023.

${ }^{2}$ Microbiology and Molecular Biology Laboratory, Department of Biological Sciences, Indian Institute of Science Education and Research, Bhopal, India-462023.

Corresponding author: vikas@iiserb.ac.in; maha@iiserb.ac.in.

\section{SUPPORTING INFORMATION}




\section{Contents}

Experimental Section

a) Reagents and Chemicals $\quad 4$

b) Peptide Synthesis 4

c) Peptide Labeling with Fluorescent Probes 4

d) Calculation of Fluorescent Dye Labeling Efficiency 5

e) Peptide Purification and Mass Spectrometric Analysis 6

f) Peptide Folding and Circular Dichroism (CD) Experiments 6

g) Steady State Förster Resonance Energy Transfer (FRET) 6

h) Unlabeled and Labeled Peptide Titration Experiments 7

i) Anisotropy and Lifetime Measurements $\quad 7$

j) Colorimetric Assay using PDA Vesicles 7-8

i) Vesicle Preparation 7

ii) Colorimetric Measurements 8

iii) Fluorescence Measurements 8

iv) Data Analysis 8

k) Pore Forming Activity by Planar Lipid Bilayer Experiments 9

1) In vivo Expression, Spot Assay, and Bacterial Growth Curve Analysis 10

\section{Supplementary Notes}

Fluorophore labeling does not affect the peptide spectroscopic properties or conformational switch of $\mathrm{TM} 1^{\mathrm{PG}}$.

Analysis of FRET measurements and interpretation of peptide titration experiments.

PDA vesicle assays and interpretation of anisotropy measurements in PDA and DMPC/PDA experiments.

Planar lipid bilayer studies, and controlled $\mathrm{TM}^{\mathrm{PG}}$ oligomerization in the membrane.

Interpretation of electrophysiology measurements and demarcation of peptide association and membrane disruption events. 
List of Peptides and Holin Constructs

Supplementary Figures

Figure S1 Mass spectrometric analysis of peptides

Figure S2 Far-UV CD spectra of all TM1 peptides

Figure S3 Secondary structure content assessed using CD

Figure S4 CD measurements of labeled peptides in LDAO and DPC

Figure S5 Influence of labeling on the anisotropy and lifetimes

Figure S6

Steady state FRET of A-TM1 and D-TM1 with change in LDAO and DPC concentration

Figure S7 Change in the average emission wavelength of the FRET acceptor

Figure S8 Summary of the dependence of acceptor fluorescence in DPC

Figure S9

Colorimetric assay of peptide-membrane association using PDA and DMPC/PDA vesicles

Figure S10

Change in Trp anisotropy in presence of PDA and DMPC/PDA vesicles

Figure S11

Change in Trp fluorescence upon association with PDA and

Figure S12 DMPC/PDA vesicles

Planar lipid bilayer measurements for membrane association and pore formation by TM1

Figure S13 Pore closing events of TM1 by planar lipid bilayer experiments

Figure S14 Planar lipid bilayer measurement of $\mathrm{TM} 1^{\mathrm{AA}}$ in the presence of a $\mathrm{pH}$ gradient

Figure S15 Western blot analysis of full-length holin and its mutant 


\section{Experimental Section}

\section{a) Reagents and Chemicals:}

All reagents and chemicals were obtained in their purified form from Sigma-Aldrich Co. LLC and used as is. Rink Amide AM resin (200-400 mesh, 0.63 mmol loading capacity) was obtained from Novabiochem (EMD Millipore Chemicals). Fmoc-amino acids and HATU ((dimethylamino)-N,N-dimethyl (3H- [1,2,3] triazolo [4,5-b] pyridin-3-yloxy) methaniminium hexafluorophosphate) were obtained at $>98 \%$ purity from GL Biochem Shanghai Ltd. Alexa Fluor® 350 and dansyl chloride (5-(dimethylamino) naphthalene-1-sulfonyl chloride) were purchased from Molecular Probes ${ }^{\circledR}$ (Life Technologies). All lipids and detergents were procured from Avanti Polar Lipids (Alabaster, AL). Other chemicals were purchased from Merck Specialties Pvt. Ltd. as highly pure forms.

\section{b) Peptide Synthesis:}

Peptides described in this study are listed in Table S1. Peptides were synthesized by solid phase synthesis using Fmoc chemistry on Rink Amide AM Resin with 0.63 mmol/g loading capacity, using dry dimethylformamide (DMF), as reported earlier. ${ }^{1}$ Deprotection of Fmoc was achieved using 20\% piperidine in DMF. Progress of the reaction was monitored using Kaiser test and mass spectrometry. The final peptide was simultaneously deprotected and cleaved from the resin using the cleavage cocktail comprising trifluoroethanol : water : phenol : thioanisole : ethanedithiol in the ratio $85: 5: 5: 5: 2.5$. The cleavage cocktail was removed using a rotary evaporator and the peptide was precipitated using cold diethyl ether. The peptide was analyzed further using mass spectrometry (described later).

\section{c) Peptide Labeling with Fluorescent Probes:}

Successfully synthesized peptide was labeled at the N-terminal end with the fluorescent probes Alexa Fluor® 350 dye or dansyl chloride.

For labeling with Alexa Fluor® 350, $1 \mathrm{mg}$ of Alexa Fluor® 350 and $5 \mathrm{mg}$ of HOBt (hydroxybenzotriazole) were dissolved in DMF and immediately added to $5 \mathrm{mg}$ of Fmocdeprotected resin. The reaction was mixed at $175 \mathrm{rpm}$ and allowed to proceed at $25^{\circ} \mathrm{C}$ for 90 min in dark. The reaction was repeated once to increase the labeling efficiency. Unlabeled Alexa Fluor ${ }^{\circledR} 350$ was finally removed by extensive washing with DMF.

For labeling with dansyl chloride, $5 \mathrm{mg}$ of Fmoc-deprotected resin was treated with $5 \mathrm{mg}$ of dansyl chloride and $30 \mu \mathrm{l}$ of DIPEA dissolved in DMF. The reaction was incubated for $90 \mathrm{~min}$ under dark at $175 \mathrm{rpm}$ rotating speed at $25{ }^{\circ} \mathrm{C}$. This step was repeated twice to improve the percentage of labeling. Unlabeled dansyl chloride was removed by extensive washing with DMF.

After completion of the labeling, the resin was processed using the cleavage cocktail, as outlined earlier, and the peptide was recovered as a powder after precipitation with diethyl ether. Success of the labeling was ascertained using mass spectrometry and dye fluorescence. 


\section{d) Calculation of Fluorescent Dye Labeling Efficiency:}

The labeling efficiency we obtained was different for the two dyes and varied across the four peptides. Hence, in order to preserve uniformity throughout the analyses, we fixed the net peptide concentration to $0.022-0.024 \mathrm{mM}$ and maintained the labeled and unlabeled peptides in a specific ratio, as described in the calculations below.

Peptide molarity calculation was carried out using its absorbance:

$$
\text { Peptide concentration }(M)=\frac{A_{280}-\left(A_{\max } \times C F_{280}\right)}{\varepsilon}
$$

Here,

$\mathrm{A}_{\max }=$ Absorbance of a labeled peptide measured at the wavelength corresponding to the $\lambda_{\max }$ of the fluorophore.

$\varepsilon=$ Peptide molar extinction coefficient.

$\mathrm{CF}_{280}=$ Correction Factor at $280 \mathrm{~nm}$; this adjusts for the amount of absorbance at $280 \mathrm{~nm}$ caused by the fluorophore.

Degree of labeling calculation:

$$
\text { Moles dye per mole peptide }=\frac{\mathrm{A}_{\max } \text { of the labeled peptide }}{\varepsilon^{\prime} \times \text { peptide concentration }(\mathrm{M})}
$$

Here, $\varepsilon^{\prime}=$ Molar extinction coefficient of the fluorophore.

Peptide concentration $=0.022-0.024 \mathrm{mM}$ (derived as described above, using $\varepsilon=8480 \mathrm{~cm}^{-1} \mathrm{M}^{-1}$ and peptide molecular weight of 2999.6 Da).

For Alexa Fluor ${ }^{\circledR} 350, \mathrm{CF}_{280}=0.40, \varepsilon^{\prime}=19,000 \mathrm{~cm}^{-1} \mathrm{M}^{-1}$ and fluorophore molecular weight $=$ 410.35 Da.

The labeling efficiency of Alexa Fluor ${ }^{\circledR} 350$ was calculated and adjusted such that the concentrations of unlabeled-to-labeled peptides were in the ratio 1:0.45.

For dansyl chloride, $\mathrm{CF}_{280}=0.59, \varepsilon^{\prime}=3300 \mathrm{~cm}^{-1} \mathrm{M}^{-1}$, and fluorophore molecular weight $=269.75$ Da.

The labeling efficiency of dansyl chloride was calculated and adjusted such that the concentrations of unlabeled-to-labeled peptides were in the ratio 1:0.54. 


\section{e) Peptide Purification and Mass Spectrometric Analysis:}

Owing to its length and extreme hydrophobicity, the peptide was poorly soluble in regular solvent systems used for purification, such as methanol, acetonitrile, ethyl acetate, chloroform, propanol etc. Hence, all peptides (labeled and unlabeled) were purified by multiple washes (3-4 times) using diethyl ether, to remove small molecule impurities, as reported earlier. ${ }^{1}$ The peptides were then lyophilized and recovered as white powders. Sample purity and successful labeling were assessed and confirmed by high resolution MALDI-ToF mass spectrometry (Figure S1).

\section{f) Peptide Folding and Circular Dichroism (CD) Experiments:}

Desired quantity of peptide in the powder was dissolved in $100 \mathrm{mM}$ LDAO (lauryldimethylamine oxide; critical micelle concentration $(C M C) \approx 1-2 \mathrm{mM}$ ) or $100 \mathrm{mM} \mathrm{DPC}$ ( $n$-dodeyclphosphocholine; $\mathrm{CMC}=1.1 \mathrm{mM}$ ) micelles prepared in $50 \mathrm{mM}$ sodium phosphate buffer $\mathrm{pH}$ 7.2, and were subjected to repeated cycles of heating and vortexing to promote peptide folding. All biophysical experiments were carried out using 0.022-0.024 mM samples, unless otherwise specified. The detergent concentrations were maintained above the CMC for both LDAO and DPC, to ensure that both detergents were predominantly in the micellar form during all our spectroscopic measurements. Quantification was achieved using a molar extinction coefficient of $8408 \mathrm{M}^{-1} \mathrm{~cm}^{-1}$ at $280 \mathrm{~nm}$. Circular dichroism (CD) data were acquired on a JASCO J815 CD spectropolarimeter (Jasco Inc., Japan), as reported earlier. ${ }^{1}$ Briefly, wavelength scans were acquired in the far-UV CD region using $0.022-0.024 \mathrm{mM}$ samples at $25^{\circ} \mathrm{C}$, using a $1 \mathrm{~mm}$ path length quartz cuvette, at $100 \mathrm{~nm} / \mathrm{min}$ scan speeds and $1 \mathrm{~s}$ data integration time. All data were averaged over three acquisitions, blank subtracted and smoothened using the MeansMovement method. For thermal denaturation measurements, data were acquired every $5{ }^{\circ} \mathrm{C}$ between $5{ }^{\circ} \mathrm{C}-95{ }^{\circ} \mathrm{C}$ at an increment of $1{ }^{\circ} \mathrm{C} / \mathrm{min}$, using the parameters described above. Recovery from thermal denaturation was acquired from $95^{\circ} \mathrm{C}-5^{\circ} \mathrm{C}$, at similar ramp rates as the denaturation experiments. All corrected data were converted to molar ellipticity values using the formula reported earlier. ${ }^{1}$

\section{g) Steady State Förster Resonance Energy Transfer (FRET):}

Alexa Fluor ${ }^{\circledR} 350\left(\lambda_{\text {ex }}=340-345 \mathrm{~nm}\right)$ and dansyl chloride $\left(\lambda_{\text {ex }}=330-340 \mathrm{~nm}\right)$ can both act as good FRET acceptors for tryptophan, allowing us to monitor steady state FRET. These experiments were carried out on a FluoroMax-4 spectrofluorometer from Horiba Jobin-Yvon, France. Excitation of Trp was set at $280 \mathrm{~nm}$, to minimize the direct excitation of the FRET acceptor; emission spectra were recorded from 295-550 nm. Excitation and emission slit widths were set as $\pm 2 \mathrm{~nm}$ and $\pm 3 \mathrm{~nm}$ respectively. Each spectrum was blank subtracted and corrected for dark counts. All experiments were performed multiple times using freshly prepared samples, to check for data reproducibility. 


\section{h) Unlabeled and Labeled Peptide Titration Experiments:}

To differentiate between inter- and intramolecular FRET signals in peptide samples carrying either fluorophore, we carried out titration experiments of the unlabeled peptide into preparations containing the labeled peptide. By considering a starting ratio of peptide: fluorophore as $1: 1$, this sample was diluted further by adding unlabeled peptide to obtain the final ratios of 1:0.8, 1:0.6, 1:4, 1:0.2, 1:0. Fluorescence spectra were recorded as described in the previous section, data were normalized against Trp emission intensity and the FRET acceptor intensities at $\lambda_{\max }$ were plotted (Alexa Fluor ${ }^{\circledR} 350 \lambda_{\max }=442 \mathrm{~nm}$ and dansyl chloride $\lambda_{\max }=500$ $\mathrm{nm})$.

\section{i) Anisotropy and Lifetime Measurements:}

Tryptophan anisotropy was measured on a FluroMax-4 spectrofluorometer (Horiba Jobin-Yvon, France), as reported earlier. ${ }^{1}$ Briefly, samples were excited using a $\lambda_{\text {ex-max }}=295 \mathrm{~nm}$ for tryptophan, and emission was recorded at $345 \mathrm{~nm}$, with a $\pm 5 \mathrm{~nm}$ slit width and a $5 \mathrm{~s}$ integration time, for both the labeled and unlabeled peptides. All sample concentrations were maintained at $\sim 0.022-0.024 \mathrm{mM}$, as for other experiments, and were determined at $280 \mathrm{~nm}$ using a molar extinction coefficient of $8480 \mathrm{M}^{-1} \mathrm{~cm}^{-1}$; this yielded an $\mathrm{A}_{295}=0.1$, for all fluorescence measurements.

Lifetime data were acquired on a DeltaFlex-01-DD (Horiba Jobin-Yvon, France) using time correlated single photon counting; tryptophan excitation at $292 \mathrm{~nm}$ was achieved using a DeltaDiode-290 pulsed LED, and fluorescence decays were measured at the respective emission maxima $\left(\lambda_{\text {em-max }}\right)$ of the various samples in steady state fluorescence measurements; ie., $345 \mathrm{~nm}$, $347 \mathrm{~nm}$ or $355 \mathrm{~nm}$, for protein samples prepared in $50 \mathrm{mM}$ sodium phosphate buffer containing LDAO (lauryldimethylamine oxide), DPC (n-dodecylphosphocholine) or no detergent, respectively. Instrument response function was measured to be $\sim 845 \mathrm{ps}$, using LUDOX AS-40. Lifetimes $\left(\tau_{\mathrm{i}}\right)$ and the corresponding amplitude functions $\left(\alpha_{\mathrm{i}}\right)$ were derived by fitting the data obtained to a triple exponential decay function on the DAS6 v6.4 software. Lifetimes were measured for at least three independent experiments; a representative dataset is presented. The average lifetime was given as $\langle\tau\rangle=\Sigma \tau_{\mathrm{i}} . \alpha_{\mathrm{i}}$.

\section{j) Colorimetric Assay using PDA Vesicles: \\ i) Vesicle Preparation:}

PDA (polydiacetylene) vesicles were prepared by resuspending 10, 12-tricosadiynoic acid in $2 \mathrm{mM}$ Tris- $\mathrm{HCl}$ buffer $\mathrm{pH} 8.5$ by sonication using a bath sonicator, at $70{ }^{\circ} \mathrm{C}$ for $20 \mathrm{~min}$, followed by overnight incubation at $4{ }^{\circ} \mathrm{C}$. Subsequently, the solution was irradiated under UV for 10 min to induce polymerization, till the solution attained an intense blue color, indicating the formation of cross-linked PDA vesicles. For the preparation of DMPC/PDA vesicles, DMPC (1,2-dimyristoyl-sn-glycero-3-phosphocholine) vesicles were first prepared using $1 \mathrm{~min}$ cycles of heating at $45{ }^{\circ} \mathrm{C}$ and vortexing, for a total of $\sim 45 \mathrm{~min}$. Following this, the DMPC vesicles were passed 20 times through a mini-extruder equipped with a membrane containing a $100 \mu \mathrm{m}$ 
diameter pore, at $25{ }^{\circ} \mathrm{C}$. DMPC vesicles that were thus formed were mixed with presonicated 10, 12-tricosadiynoic acid in 1:3 ratio, and subjected to sonication for $10 \mathrm{~min}$ at $70^{\circ} \mathrm{C}$, following the same procedure as that outlined for the preparation of PDA vesicles.

\section{ii) Colorimetric Measurements:}

PDA and DMPC/PDA vesicle concentrations were maintained as $1 \mathrm{mM}$ in $2 \mathrm{mM} \mathrm{pH} 8.5$ Tris- $\mathrm{HCl}$ buffer. Peptides were prepared in $50 \mathrm{mM}$ DPC in $50 \mathrm{mM}$ sodium phosphate buffer $\mathrm{pH}$ 7.2 and their concentrations were maintained at $0.1 \mathrm{mM}$ after 20 -fold dilution from the peptide stock. Colorimetric measurements were carried out on a SpectraMax Plus 384 microplate reader (Molecular Devices, LLC). To calculate the extent of blue to red color transitions for all vesicle samples, the colorimetric response (\% CR) was derived as follows:

$$
\% \mathrm{CR}=\left[\left(\mathrm{PB}_{0}-\mathrm{PB}_{1}\right) / \mathrm{PB}_{0}\right] \times 100
$$

where $P B=\left(A_{\text {blue }} /\left(A_{\text {blue }}+A_{\text {red }}\right)\right)$. Here, $A_{\text {blue }}$ is the absorbance of the blue component at $640 \mathrm{~nm}$ and $\mathrm{A}_{\text {red }}$ is absorbance of the red component at $520 \mathrm{~nm}$. $\mathrm{PB}_{0}$ is the blue/red ratio of the blank and $\mathrm{PB}_{1}$ is the value obtained from the peptide samples.

\section{iii) Fluorescence Measurements:}

Fluorescence experiments were performed immediately after addition of PDA or DMPC/PDA vesicles in to peptide samples on a FluoroMax-4 spectroflurometer (Horiba Jobin Yvon Ltd.). For steady state fluorescence measurements, tryptophan was excited at $295 \pm 3 \mathrm{~nm}$ and emission spectra were recorded from 310-400 $\pm 3 \mathrm{~nm}$. Data were collected at every $0.5 \mathrm{~nm}$ with a $0.1 \mathrm{~s}$ integration time. All data were blank subtracted and averaged over 3 accumulations. Steady state anisotropy kinetics were recorded as a function of time using tryptophan excitation of $295 \mathrm{~nm}$ the anisotropy was monitored at $345 \mathrm{~nm}$ with a slit width of $5 \mathrm{~nm}$. Data were recorded every $38 \mathrm{~s}$ for a period of $1 \mathrm{~h}$. In addition to anisotropy, the S1_vv component, which records the change in fluorescence intensity with time, was also checked. Steady state fluorescence kinetics (total fluorescence) were recorded as a function of time using tryptophan excitation of $295 \mathrm{~nm}$ the anisotropy was monitored at $345 \mathrm{~nm}$, with a slit width of $3 \mathrm{~nm}$. Data were recorded every $6 \mathrm{~s}$ with $0.1 \mathrm{~s}$ integration time. All data were recorded in the anti-photobleach mode.

\section{iv) Data Analysis:}

Data obtained from the tryptophan anisotropy kinetics and steady state fluorescence kinetics was fitted to an exponential decay function with a constant. Anisotropy kinetics and fluorescence kinetics data of $2.5 \mathrm{mM}$ DPC in 100\% PDA samples were fitted to single exponential decay function with 3 parameters $(\operatorname{ExpDec1})$ and the same equation was followed for all DMPC/PDA sample conditions (2.5, 5 and $10 \mathrm{mM} \mathrm{DPC})$. Data obtained for $5 \mathrm{mM}$ and 10 $\mathrm{mM}$ DPC in 100\% PDA samples were fitted to double exponential decay function with 5 parameters (ExpDec2). Equations are given below: 


$$
\begin{gathered}
\text { ExpDec1, } \quad y=A 1 * \exp \left(-\frac{x}{t 1}\right)+y 0 \\
\text { ExpDec2, } y=A 1 * \exp \left(-\frac{x}{t 1}\right)+A 2 * \exp \left(-\frac{x}{t 2}\right)+y 0
\end{gathered}
$$

Here, $x, t 1$ and $t 2$ are the measurement time and times for the first and second kinetics, respectively. A1 and A2 are the amplitude functions for the first and second transitions. $y 0$ is the constant. The rates were derived from $1 / t 1$ or $1 / t 2$, and considered as $\mathrm{k} 1$ and $\mathrm{k} 2$, respectively. All the data were averaged over a minimum of 3 independent experiments and the standard deviation was calculated.

\section{k) Pore Forming Activity by Planar Lipid Bilayer Experiments:}

Black lipid membranes were generated using DiPhPC (diphytanoyl phosphatidylcholine) on a planar lipid bilayer workstation from Warner Instruments (Harvard Apparatus), placed in a Faraday cage set on a mechanically isolated table, as reported earlier. ${ }^{1} \mathrm{DiPhPC}$ was dissolved in $n$-hexadecane at a concentration of $25-50 \mathrm{mg} / \mathrm{ml}$, and bilayers were painted across a $150 \mu \mathrm{m}$ aperture generated in the septum of a Delrin cup while the voltage was maintained at $10 \mathrm{mV}$. Both the cis and trans sides of the chamber were filled with $25 \mathrm{mM}$ sodium phosphate buffer $\mathrm{pH}$ 7.2 containing $0.5 \mathrm{M} \mathrm{KCl}$. A set voltage of $10 \mathrm{mV}$ was maintained across the bilayer and 0.011 $0.012 \mathrm{mM}$ peptide was added to the cis side of the chamber. The electrical current was recorded using a $50 \mathrm{~Hz}$ filter, sampling frequency of $10 \mathrm{kHz}$, and digitized, as reported earlier. ${ }^{1}$ All data were analyzed using the pCLAMP 10.3 software (Molecular Devices, LLC) and plotted using SigmaPlot v11.0. Frequency of events (opening and closing) were calculated at every step of the increment or decrement of the observed current at the holding voltage of $10 \mathrm{mV}$, and converted into conductance (units of $\mathrm{nS}$ ).

In order to generate a $\mathrm{pH}$ gradient across the DiPhPC membrane, the trans side of the chamber was filled with $25 \mathrm{mM}$ sodium phosphate buffer $\mathrm{pH} 6.2$ containing $0.5 \mathrm{M} \mathrm{KCl}$. The cis side was maintained at $25 \mathrm{mM}$ sodium phosphate buffer $\mathrm{pH} 7.2$ containing $0.5 \mathrm{M} \mathrm{KCl}$. This generated a $\mathrm{pH}$ difference of 1 unit across the membrane. A holding voltage of $10 \mathrm{mV}$ was maintained across the membrane. Peptide was added to the cis chamber and recordings were carried out, as described above.

Upon adding the peptide into cis side of the chamber at $10 \mathrm{mV}$, the peptide starts inserting in the membrane, and we observe an increase in current, from $0 \mathrm{pA}$ to $1000 \mathrm{pA} .0 \mathrm{pA}$ is the current observed for only the membrane, when no peptide is inserted in it. $1000 \mathrm{pA}$ is the highest current obtained when the membrane is disrupted completely. For the purpose of

analysis, we have divided the process into two events. We term the first event as the membrane association event of the peptide, where the observed current slowly increases from $0 \mathrm{pA}$ to 200 $\mathrm{pA}$. The second process is rapid, where membrane disruption occurs when the current increases from $200 \mathrm{pA}$ to $1000 \mathrm{pA}$. From the point of insertion of the first peptide in the membrane, we tabulated the time taken for the current to reach $200 \mathrm{pA}$, as T1. The time taken for the peptide to achieve $1000 \mathrm{pA}$ (from $200 \mathrm{pA}$ ) is T2, and the total time (0-1000 pA) is termed as T. The same 
parameters were maintained for the data analysis of all four peptides, which was carried out over a minimum of 10 independent experiments. Opening and closing event frequency was calculated throughout the recording and converted to conductance $(\mathrm{G})$ in $\mathrm{nS}$, using the formula $\mathrm{G}=$ [observed current in pA] / [Voltage]. Here, voltage applied was $+10 \mathrm{mV}$.

\section{1) In vivo Expression, Spot Assay, and Bacterial Growth Curve Analysis:}

E. coli BL21(DE3) strain carrying the various holin constructs (both full-length and the TM1 region) in pET21b vector were grown at $37{ }^{\circ} \mathrm{C}$ in $\mathrm{LB}$ broth containing $100 \mu \mathrm{g} / \mathrm{ml}$ of ampicillin, with constant shaking at $200 \mathrm{rpm}$. The cells were induced for protein production by the addition of $1 \mathrm{mM}$ IPTG, when the optical density of the culture at $600 \mathrm{~nm}\left(\mathrm{OD}_{600}\right)$ reached 0.6. Bacterial growth was monitored with time by drawing cultures at specific time intervals and measuring $\mathrm{OD}_{600}$. Spot assays were carried out by plating $4 \mu \mathrm{l}$ of culture at various time points after induction, at specific dilutions, on LB-agar plate containing $100 \mu \mathrm{g} / \mathrm{ml}$ ampicillin. Plates were imaged after an overnight incubation at $37^{\circ} \mathrm{C}$. 


\section{Supplementary Notes}

\section{Fluorophore labeling does not affect the peptide spectroscopic properties or conformational switch of TM1 $^{\mathrm{PG}}$.}

In order to assess the nature of conformational interconversion in $\mathrm{TM} 1^{\mathrm{PG}}$, we designed FRET-based experiments by selectively labeling the N-terminus with acceptors of tryptophan fluorescence, such as Alexa Fluor ${ }^{\circledR} 350$ or dansyl chloride. The peptides were correspondingly named as A- or D-, respectively; for example, TM1 ${ }^{\mathrm{PG}}$ with an N-terminal Alexa Fluor ${ }^{\circledR} 350$ label is notated as $\mathrm{A}-\mathrm{TM} 1^{\mathrm{PG}}$. All the peptides used in the study are provided in Table S1. The corresponding mass spectra, which were recorded to confirm fluorophore labeling, are provided in Figure S1. In short peptides, the span of the transmembrane region (i.e., the region enveloped by lipid or detergent) depends critically on the hydrophobic-hydrophilic interface conferred by the chemical nature of residues in the sequence. Addition of fluorophores such as Alexa Fluor ${ }^{\circledR}$ 350 or dansyl chloride considerably alters the hydropathy of the peptide. Hence, it is crucial to assess whether the spectroscopic properties of the peptides are altered due to labeling.

Using far-UV CD spectra, we assessed the secondary structure content and the dependence of this structure on the DPR (detergent-to-peptide ratio) by titrating increasing LDAO or DPC to a fixed concentration of labeled peptide. The results indicate that labeling with Alexa Fluor ${ }^{\circledR} 350$ does not alter the behavior of the peptide in various DPRs (Figure S4). We further verified this by measuring the dependence of anisotropy and lifetime values for the four peptides to increasing LDAO (Figure S5). As the DPR is increased, we observe a rapid increase in Trp lifetime, as the lipid or detergent effectively buries the indole moiety. This also results in a reduction in the anisotropy, as the indole attains conformational flexibility upon lipid solvation. We observe matching behavior for $\mathrm{TM} 1^{\mathrm{PG}}, \mathrm{A}-\mathrm{TM} 1^{\mathrm{PG}}$ and $\mathrm{D}-\mathrm{TM} 1^{\mathrm{PG}}$, indicating that peptide properties in LDAO are not altered upon tagging with the fluorophore (Figure S5). The same observation is extended for $\mathrm{TM} 1^{\mathrm{AA}}, \mathrm{TM} 1^{\mathrm{dPG}}$ and $\mathrm{TM} 1^{\mathrm{UG}}$ (Figure S5).

When DPC is used as the refolding medium, the overall behavior of all four peptides labeled with Alexa Fluor ${ }^{\circledR} 350$ matches very well with the unlabeled counterparts. We observe marginal differences in D-TM1 ${ }^{\mathrm{AA}}$ in LDAO and all four dansyl chloride-labeled peptides in DPC, when we compare the lifetimes and the anisotropy data (Figure S5). However, the far-UV $\mathrm{CD}$ spectra of the peptides indicate that there is no change in the secondary structure content. Furthermore, when we examine the average emission wavelength $(<\lambda>)$, the results are very similar (see Figure S7). Hence, we conclude that labeling with dansyl chloride has a negligible effect on the spectroscopic properties of the four peptides. Additionally, the observation of similar behavioral tendency for the labeled and unlabeled peptides allows us to confidently interpret the comparative studies in these sequences. 


\section{Analysis of FRET measurements and interpretation of peptide titration experiments.}

By and large, FRET measurements are presented in terms of FRET efficiency. However, in our experiments, we are unable to achieve complete labeling of the peptide, due to the poor chemical reactivity of the $\mathrm{N}$-terminal amide in our peptide. We attribute this to the highly hydrophobic nature of our peptide, which can sterically occlude the N-terminus from being modified with the fluorophore. Because of the low labeling efficiency of the parent peptides, we were unable to carry out reliable FRET efficiency calculations. Hence, in all our FRET experiments, we have maintained a constant mole ratio of unlabeled to labeled peptides, and have normalized our data to the fluorescence spectrum of the donor (tryptophan).

Our FRET data could be, in principle, a measure of contributions from both intermolecular and intramolecular energy transfers. Intramolecular FRET is the desired energy transfer mechanism. However, intermolecular FRET can occur when the peptides aggregate by forming $\beta$-sheet assemblies instead of $\beta$-hairpin assemblies. Such $\beta$-sheet assemblies are favorably formed in antiparallel fashion, as a result of which the $\mathrm{N}$ - and the C-termini are placed in close proximity. This places the fluorescence donor (tryptophan, at the C-terminus) in close proximity to the fluorescence acceptor (Alexa Fluor ${ }^{\circledR} 350$ or dansyl chloride) tagged at the Nterminus. Hence, to demarcate intramolecular FRET from intermolecular FRET, we titrated the labeled peptide with increasing amounts of the unlabeled peptide, while preserving the DPR and the peptide concentrations. The $\beta$-sheet aggregates or oligomers of the labeled peptide, if present, would undergo very slow exchange with the unlabeled peptide, since the process of disruption and re-formation of multiple hydrogen bonds is a slow and unfavorable event under ambient conditions. Such samples, therefore, would give rise to a non-linear dependence to the unlabeled peptide concentration. However, if there were negligible amounts of oligomers in solution, the dependence of FRET to the unlabeled peptide concentration would be linear. In other words, in our experiments, intramolecular FRET would respond linearly to the addition of unlabeled peptide, whereas intermolecular FRET would show a non-linear dependence. We show that the FRET data are linearly proportional to the concentration of labeled peptide, and conclude that it is the intramolecular FRET that is primarily being measured in our experiments. Further, the data also show that there is a negligible population of peptide oligomers in our TM1 peptides, in micelle samples. 


\section{PDA vesicle assays and interpretation of anisotropy measurements in PDA and DMPC/PDA experiments.}

Polydiacetylene (or PDA) is prepared by the UV-catalyzed polymerization of 10, 12 tricosadiynoic acid. This cross-linking process converts the milky white solution of tricosadiyonic acid to an intense blue color, which can now absorb light at $640 \mathrm{~nm}$. This intense blue color is preserved when PDA is mixed with lipid such as DMPC, but is converted to a red color (with absorbance at $520 \mathrm{~nm}$ ) when PDA is perturbed. In our experiments, this occurs when peptide or DPC intercalates with the PDA vesicle. PDA retains its blue color in the presence of proteins or peptides that do not interact with the membrane. However, a change from blue $\rightarrow>$ red color is achieved only when an integral membrane peptide or protein intercalates with PDA. This change in the colorimetric property of vesicles arises due to the alteration of the conjugated PDA backbone and molecular re-arrangement of the hydrophobic tail of PDA matrix upon peptide interaction.

PDA vesicles are designed to show changes in their spectroscopic properties, and serve as an excellent colorimetric tool to monitor peptide-vesicle interaction in our TM1 analogs. They have previously been used as excellent sensors of reactions involving biomolecular binding to membranes. ${ }^{2-6}$ In our experiments, we are able to demarcate the contribution of DPC and the peptide when detergents or protein/peptide molecules are interspersed with the cross-linked PDA molecules, since we measure the spectroscopic properties of PDA vesicles when either DPC or peptide is varied. We further validate this observation by measuring other intrinsic properties of the peptides, such as Trp fluorescence (total fluorescence and S1_vv) and Trp anisotropy (explained below).

Our findings with PDA and DMPC/PDA vesicles are further validated by the changes in the intrinsic Trp anisotropy of the four TM1 analogs. When the mobility of tryptophan decreases, the rate at which the excited fluorophore reorients in the excited state (during experimental timeframe) is also lowered. Hence, the anisotropy increases. Higher anisotropy value is, therefore, indicative of immobile indole. In DPC, all peptides display high anisotropy and fluorescence values. Immediately after the DPC-peptide micelles are added to the PDA or DMPC/PDA system, we observe that Trp anisotropy is significantly lowered. For example, in the case of $\mathrm{TM} 1^{\mathrm{PG}}$ refolded in $10 \mathrm{mM}$ DPC, the indole anisotropy is $\sim 0.10$ (Figure 3B, of the main text). When this peptide is added to PDA vesicles (left extreme bottom panel of Figure S10a), the initial anisotropy we record at time zero is 0.078 . This reflects an increase in the dynamicity of tryptophan immediately after the DPC-peptide complex is added to the PDA (or DMPC/PDA) vesicle. Such reduction in anisotropy indicates that the indole is no longer micelle or lipid coated, and can undergo free rotation at the side chain $C^{\alpha}-C^{\beta}$ and $C^{\beta}-C^{\gamma}$ bonds. The anisotropy slowly recovers over 10-15 minutes to values similar to those observed in DPC. This slow timeframe reasonably coincides with the time required for blue $\rightarrow$ red conversion in our PDA or DMPC/PDA colorimetry experiments.

Taken together, our anisotropy data and the colorimetric assays strongly indicate that the peptide-PDA association can be a two-step event. First, DPC+peptide micelles fuse with the 
vesicle, due to which the peptide attains an adsorbed DPC-depleted state. This process is rapid (in seconds-minutes) and gives rise to the sudden decrease in anisotropy. This is followed by a slow increase in the anisotropy, as the peptide integrates into the vesicle. Because of this integration, we see both the colorimetric response (blue -> red conversion) and an increase in the anisotropy of tryptophan as the indole gradually attains rigidity due to the peptide being incorporated in the membrane.

Our PDA vesicle assay is sufficiently robust to allow us to study the peptide-vesicle association event. The data is also supported by measurements from the intrinsic fluorescence property of the TM1 peptides. We do not rule out the possibility that the protein-detergent complex fuses with the membrane in a concerted manner. However, we do observe that the distribution of DPC in the membrane is very rapid, while the local re-organization of the peptide in the membrane is slower. It is therefore likely that the fusion of protein-detergent complex with the membrane follows faster kinetics as compared with the slower peptide-membrane interaction kinetics. 


\section{Planar lipid bilayer studies, and controlled $\mathrm{TM1}^{\mathrm{PG}}$ oligomerization in the membrane}

Our electrophysiology measurements are carried out in a planar lipid bilayer system. This is an extremely sensitive system that uses a single lipid bilayer painted across a $150 \mu \mathrm{m}$ aperture. This bilayer is $\sim 45-50 \AA$ in thickness and is maintained by surface tension, and optimal osmotic and pressure balances across the chambers. The formation of a single bilayer is confirmed by examining the bilayer using light - the painted bilayer appears black due to the destructive interference of light reflected from very thin surface. Minor mechanical perturbations will lead to the immediate disruption of the bilayer membrane, including the addition of molecules with detergent-like properties, which can 'dissolve' or 'pinch-off' the membrane. For example, the addition of detergents such as dodecyl $\beta$-D maltoside at concentration as low as $20 \mu \mathrm{M}$ leads to an immediate break of the membrane (the observed current shifts from $0 \mathrm{pA}$ to $1000 \mathrm{pA}$ in $<1 \mathrm{~s}$ ).

Such planar lipid bilayers or PLBs (often referred to as black lipid membranes due to their appearance) are ideal tools for the study of ion channel properties of biomolecules, including the voltage-gated channels and channel-forming peptides. In our electrophysiology measurements of TM1 analogs, we observe defined step sizes for each peptide. This arises from the bidirectional movement (conductance) of $\mathrm{K}^{+}$and $\mathrm{Cl}^{-}$ions across the membrane from one chamber to the other. Since we are studying peptides, such ion conductance is possible only with peptide oligomerization in the membrane, which leads to the formation of pores that are large enough for ion movement. The observation of stepwise conductance is not possible if any of the peptides display detergent-like properties.

The use of PLBs for the study of ion transport in transmembrane proteins and peptides is not new. For example, the outer membrane proteins from Borrelia burgdorferi P13 and Vibrio cholerae, have been studied in planar bilayers. Similarly, the human mitochondrial porin has been studied in PLB membranes. These membrane proteins belong to the porin family, and PLB measurements provide information on their pore forming behavior and ion selectivity. ${ }^{7-9}$

Our electrophysiology measurements using the planar bilayer set-up provides us with interesting insight on peptide behavior. A defined and narrow range of conductance of $\sim 0.4 \mathrm{nS}$ is obtained only for TM1 ${ }^{\mathrm{PG}}$. This is possible only if pores of defined and uniform sizes are formed in the membrane. Progressive higher order oligomeric assemblies containing varying numbers of monomer peptide units will give conductance values of diverse step sizes, as seen for TM $1^{\mathrm{UG}}$. Hence, our electrophysiology measurements in planar lipid bilayers confirm that (i) the TM1 analogs are transmembrane peptides that associate in the membrane; (ii) they do not have detergent-like behavior; (iii) they oligomerize in the membrane to form pores; (iv) oligomerization of $\mathrm{TM} 1^{\mathrm{PG}}$ in the membrane is controlled and results in the formation of defined assemblies of similar number of monomeric peptide molecules. 


\section{Interpretation of electrophysiology measurements and demarcation of peptide association and membrane disruption events.}

Using our planar bilayer measurements, we are able to demarcate the association time of the peptide after incorporation in the lipid membrane, and the time required for each TM1 analog to cause membrane disruption. In most of our experiments, we observe that below 150-250 pA, the increase in current with time, is a slow process (for example, see the PLB recordings presented in Figure S12). This is because the progressive peptide association in the DiPhPC membrane, and the formation of transient pores by peptide oligomerization depends on the peptide concentration in the membrane. The process is slow when the peptide concentration in the membrane is less. When there is sufficient accumulation of peptide in the membrane, the process of pore formation is very rapid and results in membrane disruption.

We envision that there are two distinct processes with different kinetics occurring over different timescales. We have categorized the first slow process as "association" of the peptide within the membrane, and the second process as "membrane disruption" by the peptide. Qualitative averaging of data from all four peptides allowed us to arrive at a median value of $\sim 200 \mathrm{pA}$ as the cut-off for the two processes. This cut-off of $200 \mathrm{pA}$ is also supported by the data obtained from $\mathrm{TM}^{\mathrm{AA}}$ recorded in the presence of a $\mathrm{pH}$ gradient. In this specific case, as the peptide associates in the membrane, the current increases from $0 \mathrm{pA}$. Beyond $200 \mathrm{pA}$, we see membrane re-formation (see Figure S14). Hence, beyond $\sim 200 \mathrm{pA}$, we can see either the exponential peptide association leading to membrane disruption or the membrane re-formation.

We observe two processes, one slow and one fast, in our bilayer experiments. Hence, we have calculated times $\mathrm{T} 1$ and $\mathrm{T} 2$, which correspond to membrane association and membrane disruption, respectively, by choosing $200 \mathrm{pA}$ as the demarcating point. It must be noted here that due to the rapid nature of the second event, our estimated time duration for the "membrane association" and "membrane disruption" processes would not vary considerably if we were to use a cut-off of $150 \mathrm{pA}$ or $250 \mathrm{pA}$. 


\section{List of Peptides and Holin Constructs}

Table S1. List of peptides holin constructs described in this study.

\begin{tabular}{|c|c|c|c|}
\hline \multirow{2}{*}{$\begin{array}{l}\text { Sample } \\
\text { code }^{\#}\end{array}$} & \multirow[t]{2}{*}{ Peptide/Protein Sequence $^{\#}$} & \multicolumn{2}{|c|}{ Molecular Weight (Da) ${ }^{\$}$} \\
\hline & & Expected & Observed \\
\hline TM1 $^{\text {PG }}$ & KIRETLYYVGTLVPGILGIALIWGGGIDA & 2999.711 & $3000.830\left(\mathrm{H}^{+}\right)$ \\
\hline TM1 $^{\text {dPG }}$ & KIRETLYYVGTLV ${ }^{\mathrm{D}}$ PGILGIALIWGGIDA & 2999.711 & $2999.993\left(\mathrm{H}^{+}\right)$ \\
\hline $\mathbf{T M 1}^{\mathrm{AA}}$ & KIRETLYYVGTLVAAILGIALIWGGIDA & 2988.695 & $2988.866\left(\mathrm{H}^{+}\right)$ \\
\hline $\mathrm{TM1}^{\mathrm{UG}}$ & KIRETLYYVGTLVUGILGIALIWGGIDA & 2988.695 & $2989.348\left(\mathrm{H}^{+}\right)$ \\
\hline $\mathrm{A}-\mathrm{TM1}^{\mathrm{PG}}$ & A-KIRETLYYVGTLVPGILGIALIWWGGIDA & 3295.217 & $3317.997\left(\mathrm{Na}^{+}\right)$ \\
\hline A-TM1 ${ }^{\text {dPG }}$ & A-KIRETLYYVGTLV ${ }^{\mathrm{D}}$ PGILGIALIWGGIDA & 3295.217 & $3317.864\left(\mathrm{Na}^{+}\right)$ \\
\hline $\mathrm{A}-\mathbf{T M} 1^{\mathrm{AA}}$ & A-KIRETLYYVGTLVAAILGIALIWGGIDA & 3284.201 & $3305.718\left(\mathrm{Na}^{+}\right)$ \\
\hline $\mathrm{A}-\mathrm{TM} 1^{\mathrm{UG}}$ & A-KIRETLYYVGTLVUGILGIALIWGGGIDA & 3284.201 & $3305.830\left(\mathrm{Na}^{+}\right)$ \\
\hline D-TM1 $^{\text {PG }}$ & D-KIRETLYYVGTLVPGILGIALIWGGGIDA & 3233.916 & $3234.282\left(\mathrm{H}^{+}\right)$ \\
\hline D-TM1 ${ }^{\text {dPG }}$ & D-KIRETLYYVGTLV ${ }^{\mathrm{D}}$ PGILGIALIWGGIDA & 3233.916 & $3233.930\left(\mathrm{H}^{+}\right)$ \\
\hline D-TM1 ${ }^{\text {AA }}$ & D-KIRETLYYVGTLVAAILGIALIWGGGIDA & 3221.317 & $3222.339\left(\mathrm{H}^{+}\right)$ \\
\hline D-TM1 ${ }^{\text {UG }}$ & D-KIRETLYYVGTLVUGILGIALIWGGIDA & 3221.317 & $3222.019\left(\mathrm{H}^{+}\right)$ \\
\hline $\mathrm{TM1}^{\mathrm{PG} *}$ & \multicolumn{3}{|c|}{$\begin{array}{l}\text { MGSSHHHHHHHSSGLVPRGSHMSPKIRETLYYVGTLVPGILGIALIWGGI } \\
\text { DAGAA }\end{array}$} \\
\hline TM1 $^{\text {AA* }^{*}}$ & \multicolumn{3}{|c|}{$\begin{array}{l}\text { MGSSHHHHHHHSSGLVPRGSHMSPKIRETLYYVGTLVAAILGIALIWGGI } \\
\text { DAGAA }\end{array}$} \\
\hline HolFL & \multirow{2}{*}{\multicolumn{3}{|c|}{$\begin{array}{l}\text { MSPKIRETLYYVGTLVPGILGIALIWGGIDAGAAANIGDIVAGALNLVGAA } \\
\text { APATAAVKVNQQRKDGTLTTSPVDQVTRGVEQVLAAKQNAEAEVERVK } \\
\text { QALESAVNGAVPQLGPLASQILNGIQPAYSQPFDPHTQPWNLEHHHHHH }\end{array}$}} \\
\hline TM1 $^{\text {PG* }^{*}}$ & & & \\
\hline $\begin{array}{l}\text { HolFL } \\
\text { TM1 }^{\text {AA* }}\end{array}$ & \multicolumn{3}{|c|}{$\begin{array}{l}\text { MSPKIRETLYYVGTLVAALGIALIWGGIDAGAAANIGDIVAGALNLVGAA } \\
\text { APATAAVKVNQQRKDGTLTTSPVDQVTRGVEQVLAAKQNAEAEVERVK } \\
\text { QALESAVNGAVPQLGPLASQILNGIQPAYSQPFDPHTQPWNLEHHHHHH }\end{array}$} \\
\hline
\end{tabular}

\# A-: N-terminal Alexa Fluor ${ }^{\circledR}$ labeled; D-: N-terminal dansyl labeled. The central PG segment and its substitutions in the various sequences are highlighted as red, bold. Trp (FRET donor) is underlined in the peptide sequences. 
\$ All mass spectra were recorded on an UltrafleXtreme MALDI-ToF/ToF mass spectrometer (Bruker Daltonics, Inc). The observed species (protonated or sodiated) is indicated in parentheses. Spectra are provided in Figure S1.

* E. coli BL21(DE3) strain carrying various holin constructs (both TM1 region and full-length) in $\mathrm{pET} 21 \mathrm{~b}$ vector. Sequence is provided from $\mathrm{N}$ - to C-terminus. 


\section{Supplementary Figures}

A

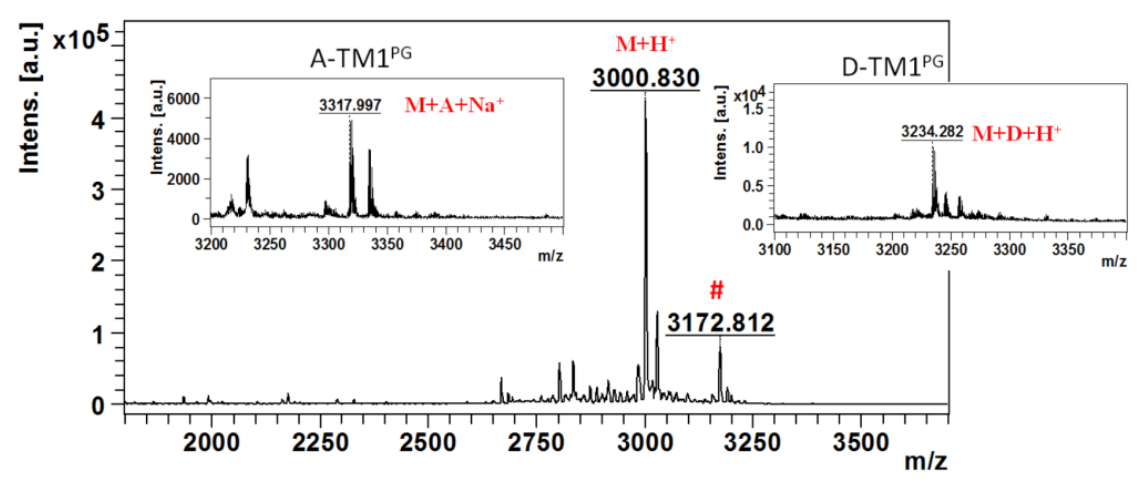

C

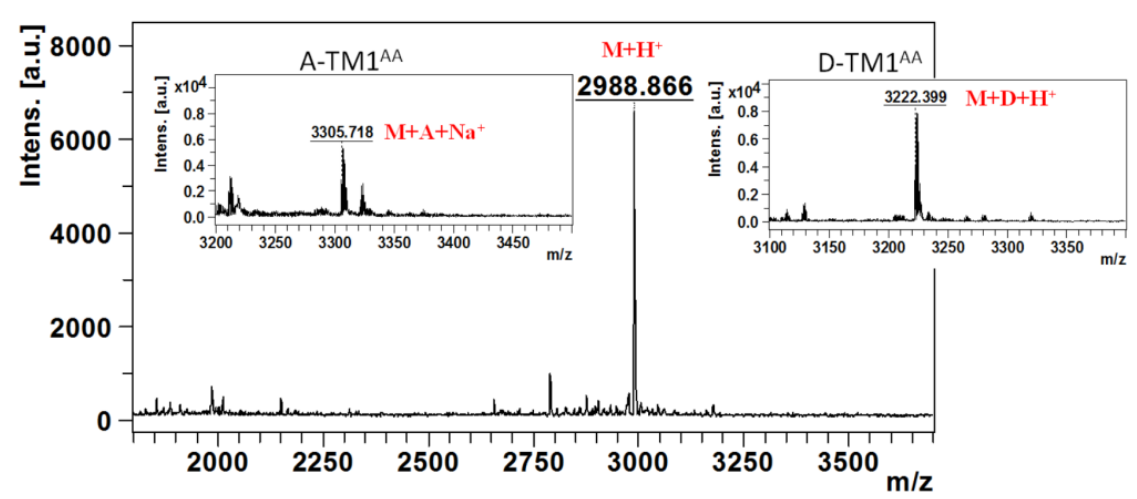

B

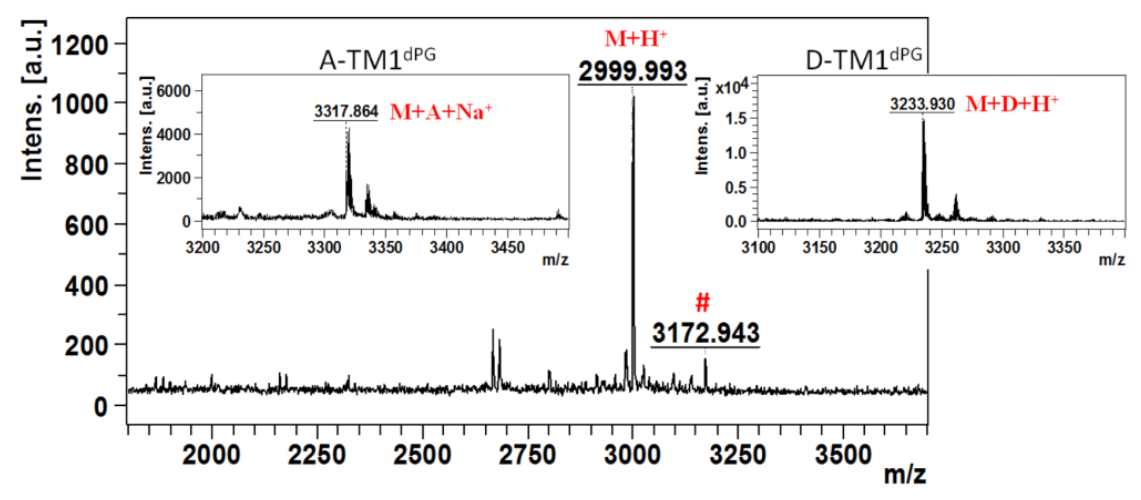

D

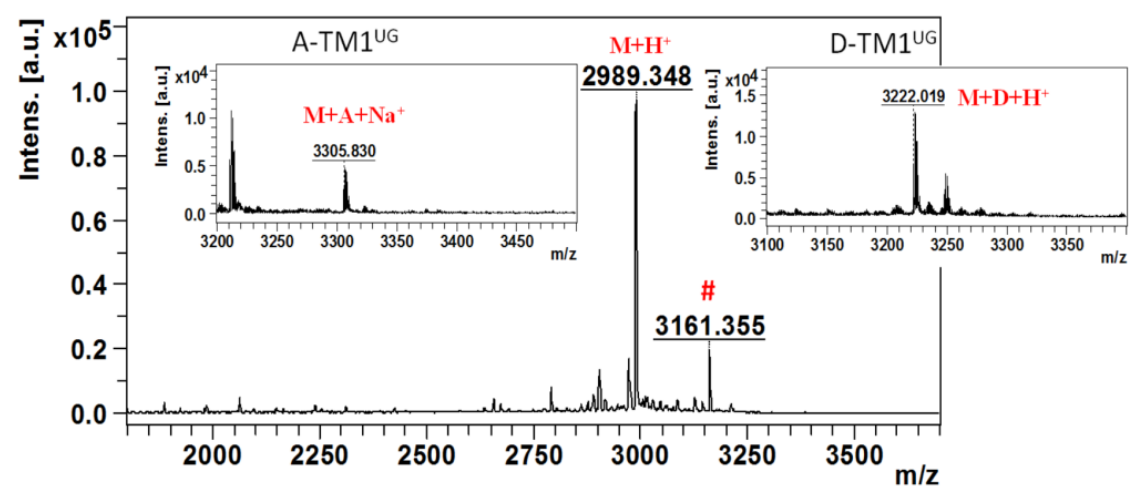

Figure S1: MALDI-ToF data. Mass data of $\mathrm{TM} 1^{\mathrm{PG}}(\mathrm{A}), \mathrm{TM}^{\mathrm{dPG}}(\mathrm{B}), \mathrm{TM} 1^{\mathrm{AA}}(\mathrm{C})$ and $\mathrm{TM} 1^{\mathrm{UG}}(\mathrm{D})$. Mass spectra of the parent peptides are presented as main figures and its labeled counterparts as insets. Alexa Fluor ${ }^{\circledR} 350$ - labeled peptides are in the left panels and dansyl labeled peptides are in the right panel in each graph. The expected molecular weights of all the peptides are mentioned in Table 1. Mass data for the parent $\mathrm{TM} 1^{\mathrm{PG}}(\mathrm{A}), \mathrm{TM}^{\mathrm{dPG}}(\mathrm{B}), \mathrm{TM}^{\mathrm{AA}}(\mathrm{C})$ were reported in a previous study, ${ }^{1}$ the spectra have been re-recorded for this study. The ethanedithiol/TFA cyclic adduct observed for some of the peptides are indicated using the octothorpe (\#). 


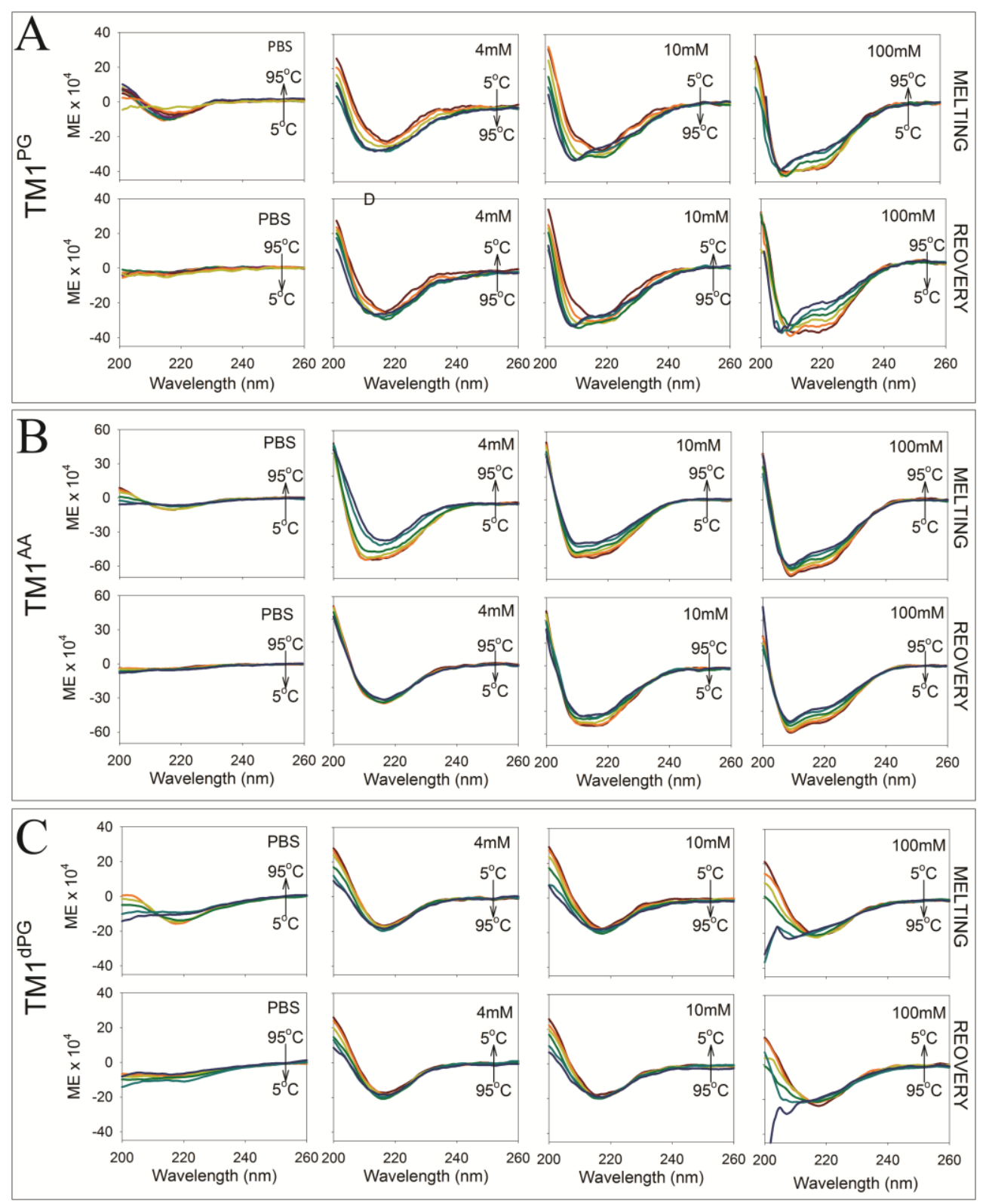

Figure S2a: Far-UV CD wavelength scans illustrating the change in secondary structure with thermal denaturation from $5{ }^{\circ} \mathrm{C}-95^{\circ} \mathrm{C}$ (melting) and $95{ }^{\circ} \mathrm{C}-5{ }^{\circ} \mathrm{C}$ (recovery) in 0 (PBS), 4 $\mathrm{mM}, 10 \mathrm{mM}$ and $100 \mathrm{mM}$ LDAO for TM1 ${ }^{\mathrm{PG}}(\mathrm{A}), \mathrm{TM}^{\mathrm{AA}}$ (B) and TM1 ${ }^{\mathrm{dPG}}(\mathrm{C})$. Complete loss of the residual secondary structure is seen in PBS sample (peptide directly resuspended in phosphate buffered solution), upon heating. At low DPRs, TM1 ${ }^{\mathrm{PG}} \mathrm{CD}$ spectra are similar to $\mathrm{TM}^{\mathrm{dPG}}$. At high DPR, TM1 ${ }^{\mathrm{PG}} \mathrm{CD}$ spectra are similar to TM1 ${ }^{\mathrm{AA}}$. Further, we have previously reported that at low DPRs (detergent-to-peptide ratio), TM1 ${ }^{\mathrm{PG}}$ shows a conformational interconversion to a helical intermediate upon heating, which is accompanied by an increase in molar ellipticity. Data for all three peptides have been reported earlier, ${ }^{1}$ and are reproduced here from Lella, M and Mahalakshmi, R. (2013) Chem. Commun. 49(83), 9594-9596, with permission from the Royal Society of Chemistry, for purpose of comparison. Mean residue ellipticity (MRE) at $5{ }^{\circ} \mathrm{C}$ for the $\beta$-hairpin at $[\theta]_{215}=-5734.43\left(\mathrm{TM} 1^{\mathrm{dPG}}\right)$, and for $\alpha$-helix at $[\theta]_{208}=-23207.7\left(\mathrm{TM}^{\mathrm{AA}}\right)$ in LDAO. ME: molar ellipticity in units of deg $\mathrm{cm}^{2} \mathrm{dmol}^{-1}$ and MRE: $\operatorname{deg~} \mathrm{cm}^{2} \mathrm{dmol}^{-1} \mathrm{res}^{-1}$. 


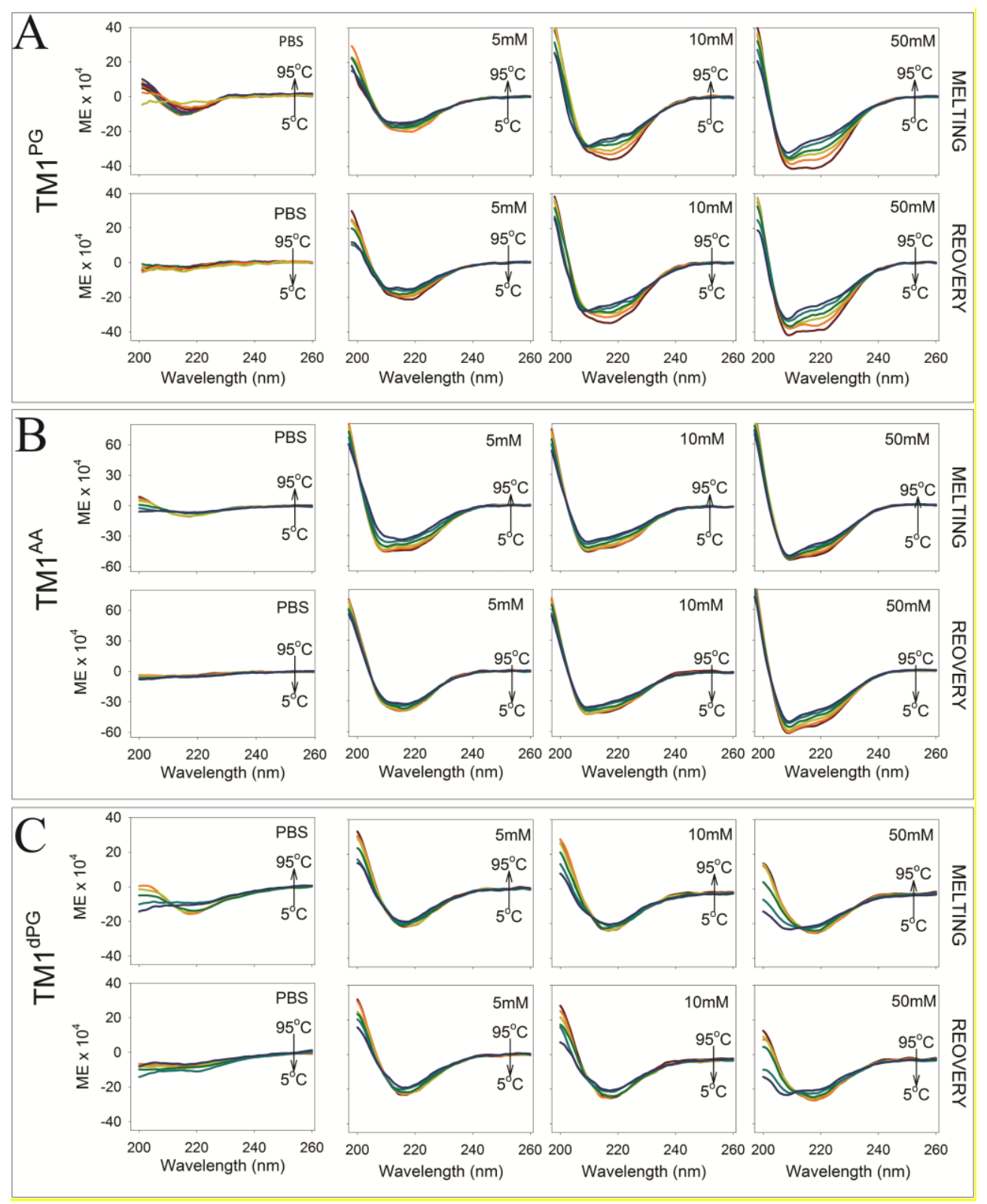

Figure S2b: Far-UV CD wavelength scans illustrating the change in secondary structure with thermal denaturation from $5{ }^{\circ} \mathrm{C}-95{ }^{\circ} \mathrm{C}$ (melting) and $95{ }^{\circ} \mathrm{C}-5{ }^{\circ} \mathrm{C}$ (recovery) in $5 \mathrm{mM}, 10$ $\mathrm{mM}$ and $50 \mathrm{mM}$ DPC for $\mathrm{TM} 1^{\mathrm{PG}}(\mathrm{A}), \mathrm{TM}^{\mathrm{AA}}(\mathrm{B})$ and $\mathrm{TM} 1^{\mathrm{dPG}}(\mathrm{C})$. Complete loss of the residual secondary structure is seen in PBS sample upon heating (data from Fig. S2a is presented here for easy comparison). As seen in LDAO, at low DPRs, TM1 ${ }^{\mathrm{PG}} \mathrm{CD}$ spectra are similar to $\mathrm{TM} 1^{\mathrm{dPG}}$. At high $\mathrm{DPR}, \mathrm{TM} 1^{\mathrm{PG}} \mathrm{CD}$ spectra are similar to $\mathrm{TM} 1^{\mathrm{AA}}$. Additionally, note that in $10 \mathrm{mM}$ DPC, TM $1{ }^{\mathrm{PG}} \mathrm{CD}$ spectrum is characteristic of a mixed $\alpha+\beta$ structure. Note that, unlike LDAO, the conformational interconversion shows a narrow DPR dependence in DPC. Further, we have previously reported that at low DPRs, TM1 ${ }^{\mathrm{PG}}$ shows a conformational interconversion to a helical intermediate upon heating, which is accompanied by an increase in molar ellipticity. On the other hand, $\mathrm{TM} 1^{\mathrm{AA}}$ undergoes irreversible denaturation in $5 \mathrm{mM}$ DPC. TM $1^{\mathrm{dPG}}$ shows reversible unfolding from $\beta$-rich to random coil-like state upon heating, in DPC $\geq 10 \mathrm{mM}$. Mean residue ellipticity (MRE) at $5{ }^{\circ} \mathrm{C}$ for the $\beta$-hairpin at $[\theta]_{215}=-7577.42$ $\left(\mathrm{TM} 1^{\mathrm{dPG}}\right)$, and for $\alpha$-helix $[\theta]_{208}=-18583.6\left(\mathrm{TM} 1^{\mathrm{AA}}\right)$ in DPC. ME: molar ellipticity in units 
of $\operatorname{deg} \mathrm{cm}^{2} \mathrm{dmol}^{-1}$ and MRE: deg $\mathrm{cm}^{2} \mathrm{dmol}^{-1} \mathrm{res}^{-1}$. Data for all three peptides have been reported earlier, ${ }^{1}$ and are reproduced here from Lella, M and Mahalakshmi, R. (2013) Chem. Commun. 49(83), 9594-9596, with permission from the Royal Society of Chemistry, for comparison purpose.

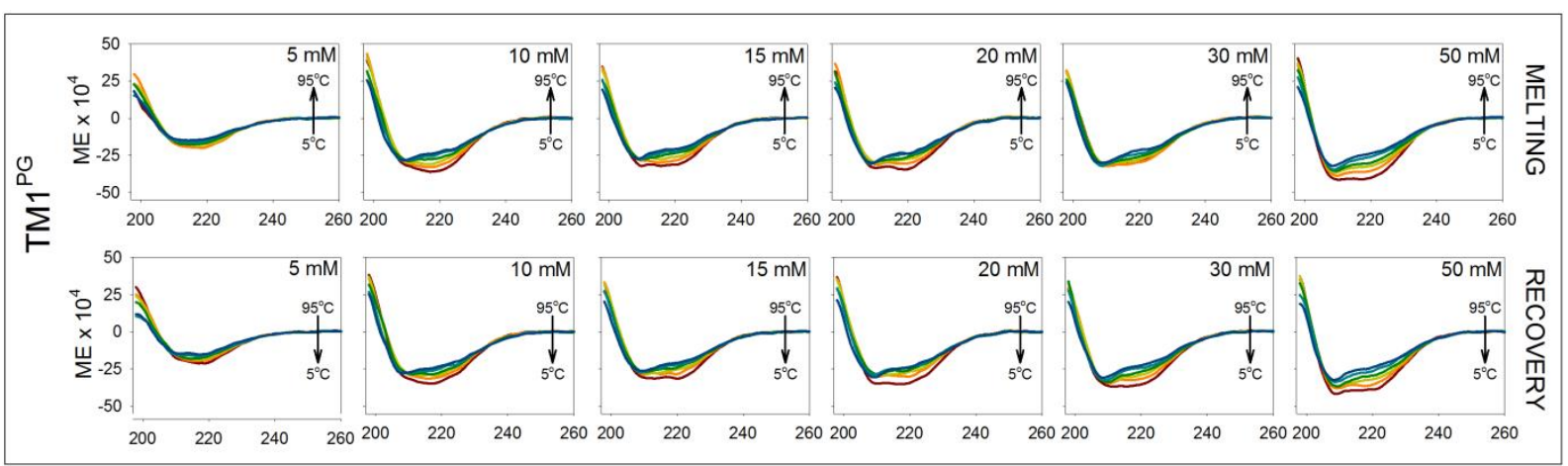

Figure S2c: Far-UV CD wavelength scans illustrating the change in secondary structure with thermal denaturation from $5{ }^{\circ} \mathrm{C}-95^{\circ} \mathrm{C}$ (melting) and $95^{\circ} \mathrm{C}-5^{\circ} \mathrm{C}$ (recovery) in 0 to $50 \mathrm{mM}$ DPC for $\mathrm{TM}^{\mathrm{PG}}$. Structural interconversion (see Figure S3a, DPC samples) showed no change at $\mathrm{ME}_{208}$ upon increasing temperature, as seen here from the overlay of wave scans at $208 \mathrm{~nm}$. A change is evident only at $215 \mathrm{~nm}$ and $222 \mathrm{~nm}$. This suggests that although the $\alpha-$ helix $\leftrightarrow \beta$-hairpin conversion is seen in the case of 5-10 mM DPC (see $\mathrm{ME}_{215}$ plot in Figure $\mathrm{S} 3 \mathrm{~b}$ ), the same information is not translated in the $\mathrm{ME}_{208}$ plots presented in Figure S3a. Mean residue ellipticity at $5{ }^{\circ} \mathrm{C}$ for the $\beta$-hairpin at $[\theta]_{215}=-5641.25$, and for $\alpha$-helix at $[\theta]_{208}=-$ 14106.9. ME: molar ellipticity in units of $\operatorname{deg} \mathrm{cm}^{2} \mathrm{dmol}^{-1}$ and MRE: $\mathrm{deg} \mathrm{cm}^{2} \mathrm{dmol}^{-1} \mathrm{res}^{-1}$. Data for $5 \mathrm{mM}, 10 \mathrm{mM}$ and $50 \mathrm{mM}$ DPC have been reported earlier, ${ }^{1}$ and are reproduced here from Lella, M and Mahalakshmi, R. (2013) Chem. Commun. 49(83), 9594-9596, with permission from the Royal Society of Chemistry, for purpose of comparison. 


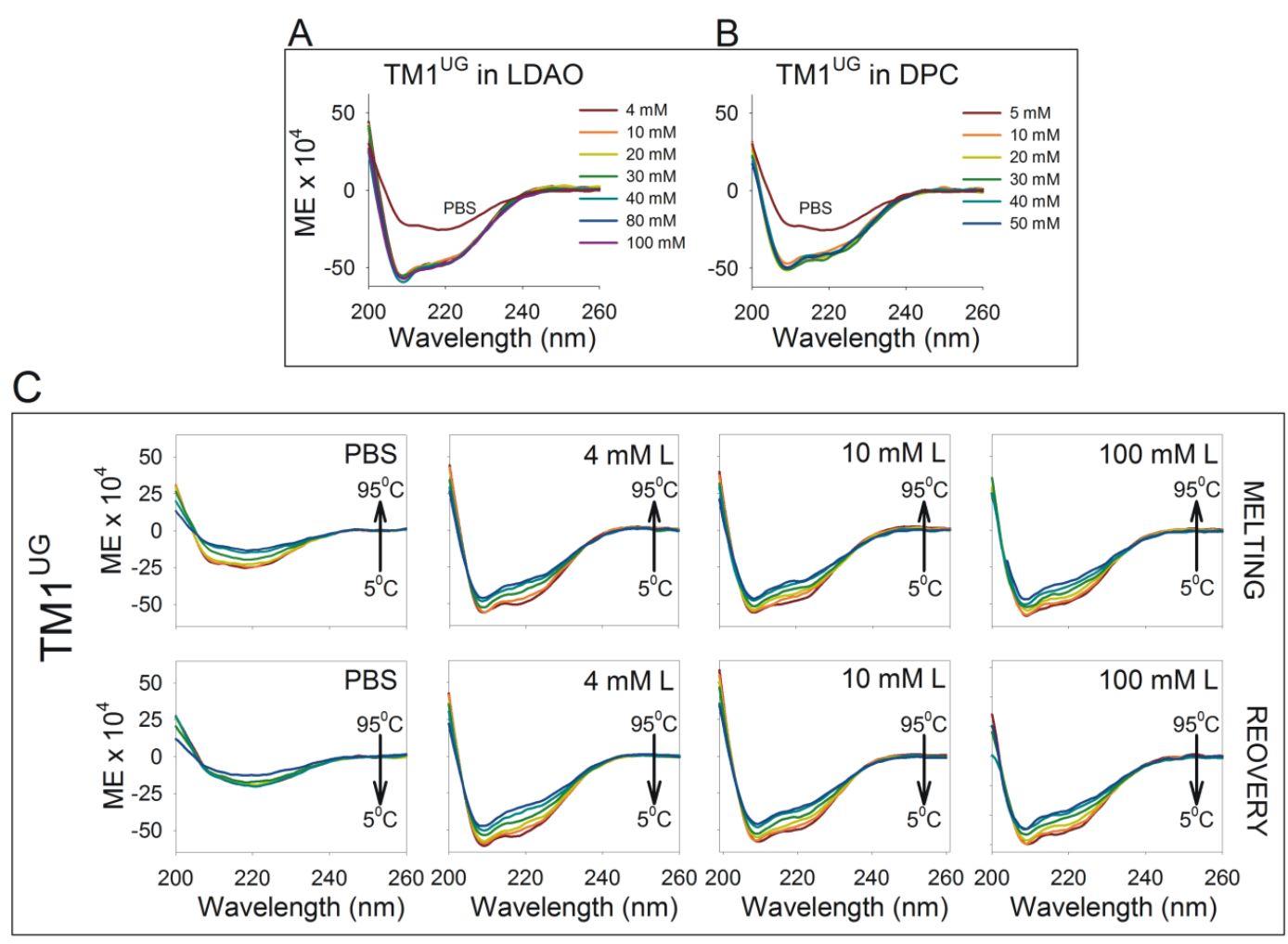

D

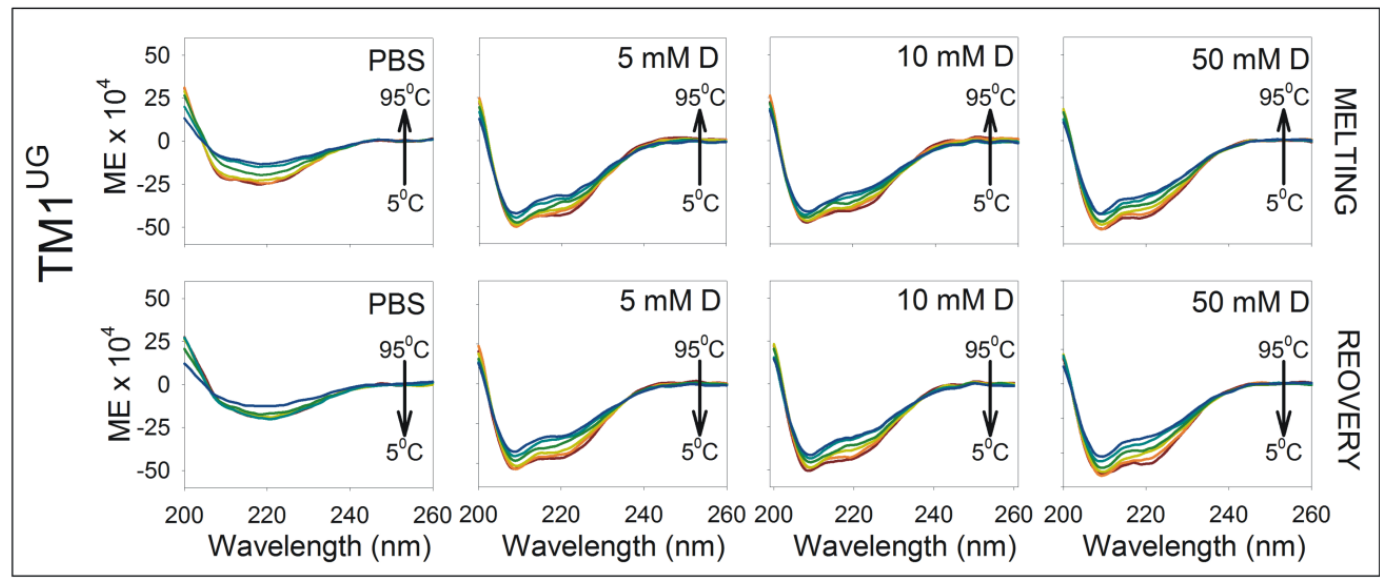

Figure S2d: Far-UV CD spectra of TM1 ${ }^{\mathrm{UG}}$. Shown here are CD spectra of this peptide recorded with increasing concentrations (and detergent-to-peptide ratios, DPRs) of LDAO (4 $\mathrm{mM}-100 \mathrm{mM}$; panel A) or DPC (5 mM - 50 mM; panel B). Also shown is the persistent residual structure in this peptide in phosphate buffer. (C and D) $C D$ wavelength scans illustrating the change in secondary structure with thermal denaturation of TM $1{ }^{\mathrm{UG}}$ from $4{ }^{\circ} \mathrm{C}$ - $95{ }^{\circ} \mathrm{C}$ (melting) and $95{ }^{\circ} \mathrm{C}-4{ }^{\circ} \mathrm{C}$ (recovery) in selected LDAO (L) or DPC (D) concentrations. Control is the response of the peptide dissolved in phosphate buffer to temperature. The corresponding far-UV CD spectra of the peptides $\mathrm{TM} 1^{\mathrm{PG}}, \mathrm{TM} 1^{\mathrm{dPG}}$ and $\mathrm{TM} 1^{\mathrm{AA}}$ have been reported earlier, ${ }^{1}$ and are now provided in Figures S2a-c. Mean residue ellipticity (MRE) at $5{ }^{\circ} \mathrm{C}$ for the $\alpha$-helix at $[\theta]_{208}=-19495.8$ in DPC. ME: molar ellipticity in units of deg $\mathrm{cm}^{2} \mathrm{dmol}^{-1}$ and MRE: deg $\mathrm{cm}^{2} \mathrm{dmol}^{-1} \mathrm{res}^{-1}$. 

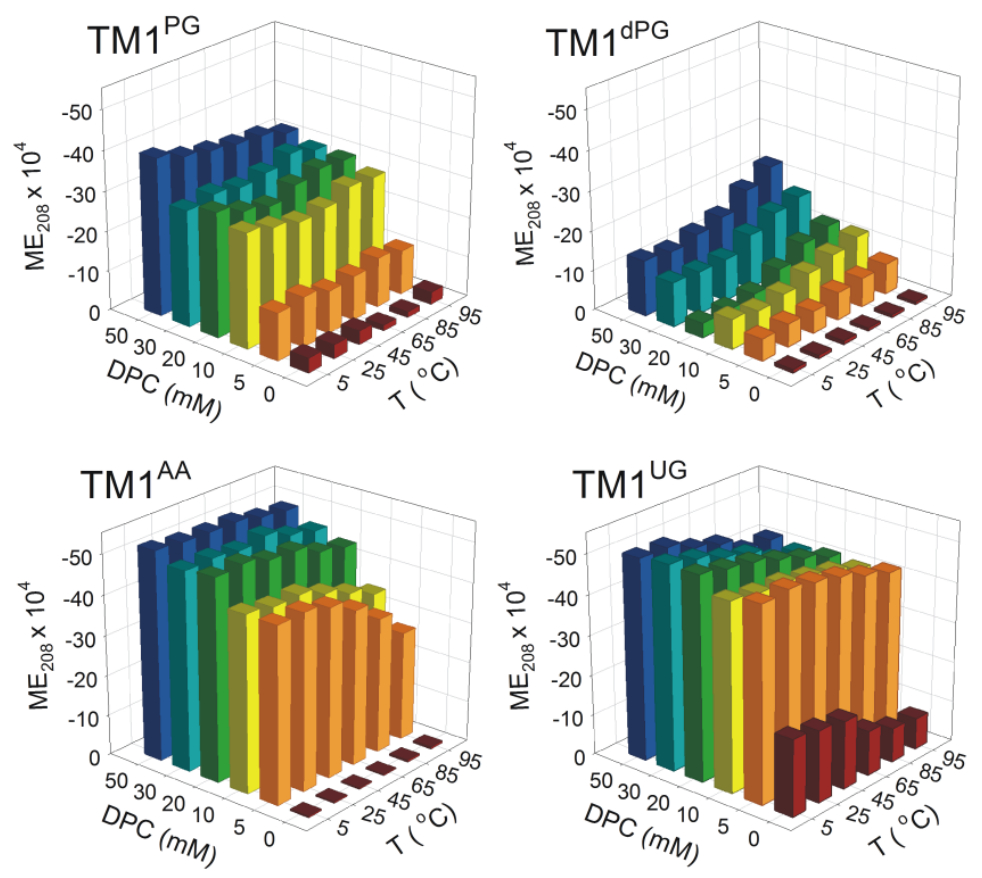

Figure S3a: Dependence of the secondary structure content assessed in DPC using CD. Changes in the far-UV CD values (molar ellipticity at $208 \mathrm{~nm}$; $\mathrm{ME}_{208}$ ) were monitored at various temperatures $\left(\mathrm{T},{ }^{\circ} \mathrm{C}\right.$ ) and detergent micelle concentrations (LDAO (Fig 1) or DPC, $\mathrm{mM}$ ) in the four peptides described in this study. Data for DPC are shown above. Note how the peptides with a well-defined secondary structure of $\alpha$-helix $\left(\mathrm{TM} 1^{\mathrm{UG}}\right)$ or $\beta$-sheet $\left(\mathrm{TM} 1^{\mathrm{dPG}}\right)$ do not display considerable changes in $\mathrm{ME}_{208}$ with temperature or DPR. However, TM1 ${ }^{\mathrm{PG}}$, which undergoes a DPR-dependent conformational switch (top left graph), shows an increase in secondary structure, as the peptide undergoes a conformational interconversion from an extended to a helical form. On the contrary, $\mathrm{TM} 1^{\mathrm{AA}}$ shows a loss in structure in low DPRs, due to irreversible aggregation. Behavior of all peptides is similar in both LDAO and DPC, indicating that the nature of the micelles does not alter the conformational preferences of these peptides. Mean residual ellipticity (MRE) at $5{ }^{\circ} \mathrm{C}$ for the $\beta$-hairpin at $[\theta]_{215}=-7577.42$ $\left(\mathrm{TM} 1^{\mathrm{dPG}}\right)$, and for $\alpha$-helix at $[\theta]_{208}=-18583.6\left(\mathrm{TM} 1^{\mathrm{UG}}\right)$. ME: molar ellipticity in units of deg $\mathrm{cm}^{2} \mathrm{dmol}^{-1}$ and MRE: $\operatorname{deg} \mathrm{cm}^{2} \mathrm{dmol}^{-1} \mathrm{res}^{-1}$. 
A
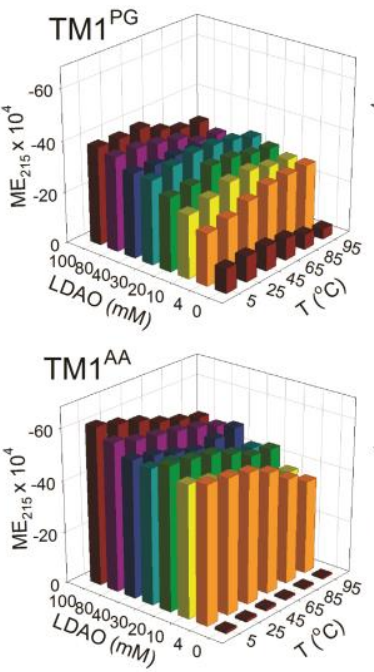
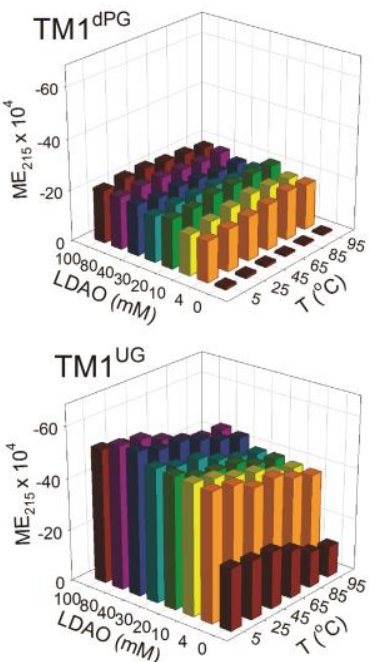

B
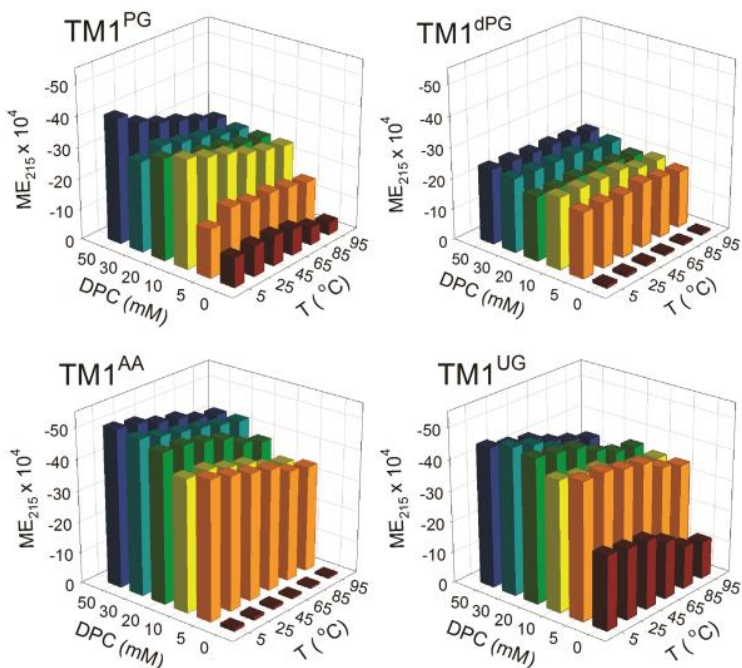

Figure S3b: Dependence of the secondary structure content assessed in LDAO (A) and DPC (B) using CD. Changes in the far-UV CD values (molar ellipticity at $215 \mathrm{~nm} ; \mathrm{ME}_{215}$, in deg $\mathrm{cm}^{2} \mathrm{dmol}^{-1}$ ) were monitored at various temperatures $\left(\mathrm{T},{ }^{\circ} \mathrm{C}\right)$ and detergent micelle concentrations (LDAO or DPC, $\mathrm{mM}$ ) in the four peptides. Peptides show a marginal (TM1 ${ }^{\mathrm{PG}}$ ) or considerable $\left(\mathrm{TM} 1^{\mathrm{AA}}\right.$ and $\mathrm{TM} 1^{\mathrm{UG}}$ ) loss in the overall secondary structure content, or no change in secondary structure content $\left(\mathrm{TM} 1^{\mathrm{dPG}}\right)$, upon heating. At low DPRs (4-10 mM LDAO), TM1 ${ }^{\mathrm{PG}}$ shows a gain in secondary structure content. The increase at $\mathrm{ME}_{208}$ (see Figure 1 of the main text) is higher than that at $\mathrm{ME}_{215}$ (shown here), suggesting that the gain in structure for this peptide is of helical nature. 
A

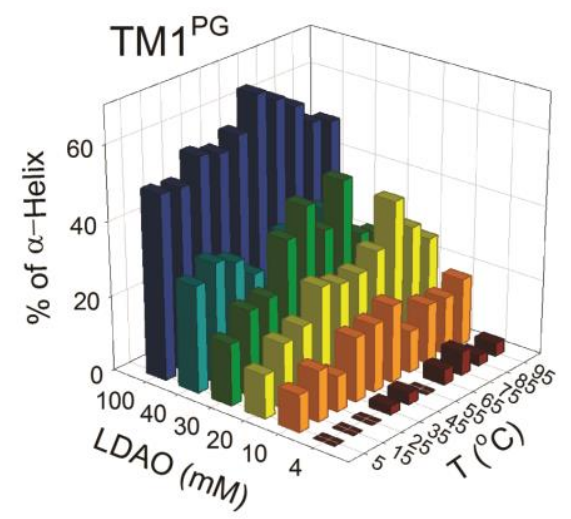

$\mathrm{B}$

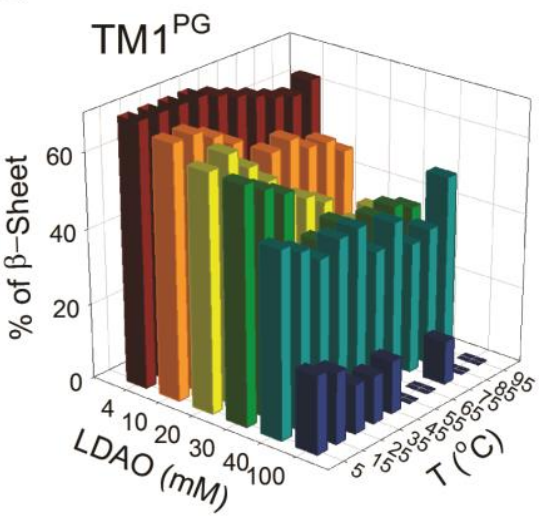

Figure S3c: Percentage of secondary structure for TM1 ${ }^{\mathrm{PG}}$ in LDAO samples (4-100 mM) with respect to increasing temperature $(\mathrm{T})$ from $5-95{ }^{\circ} \mathrm{C}$. We observe an increase in $\%$ helicity (A) and a decrease in $\%$ of the $\beta$-sheet content $(\mathrm{B})$ in $\mathrm{TM} 1^{\mathrm{PG}}$, upon increasing LDAO and temperature. Note that the LDAO axis in (A) is plotted from $100 \rightarrow 4 \mathrm{mM}$, and from 4 -> $100 \mathrm{mM}$ in (B). The secondary structure estimation was calculated by using Reed's reference from JASCO Spectra Manager Analysis software, and is shown here for one representative dataset. However, the deconvolutions are not always completely accurate, and give rise to fluctuations in the estimation, as seen here. The data for $80 \mathrm{mM}$ LDAO could not be quantified with confidence, and is omitted from the plot. Some of the far-UV CD wavelength scans from which this deconvolution was carried out, is presented in panel A of Figure S2a. 
A
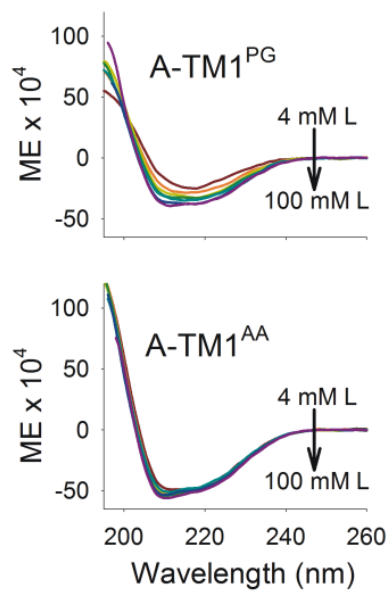

C
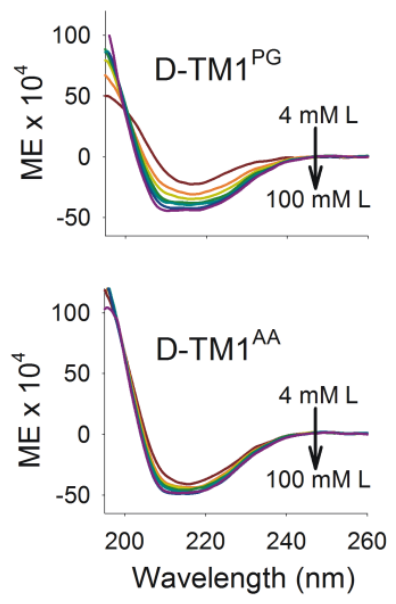
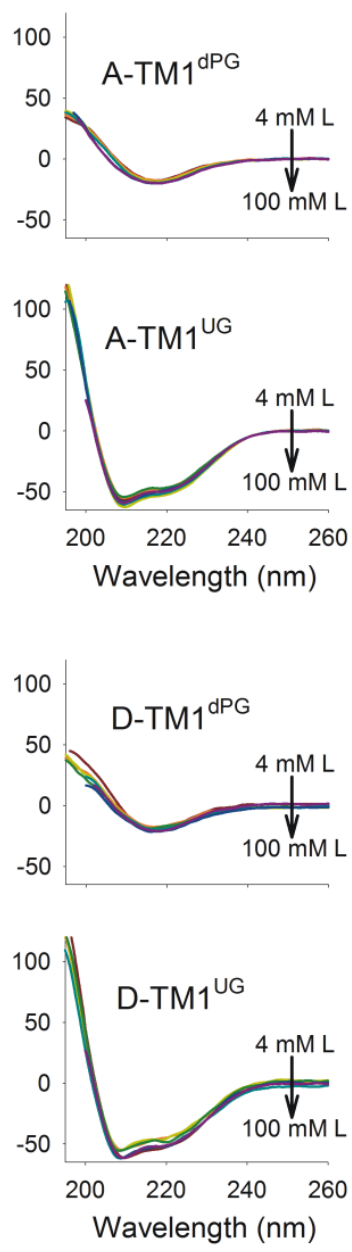

B
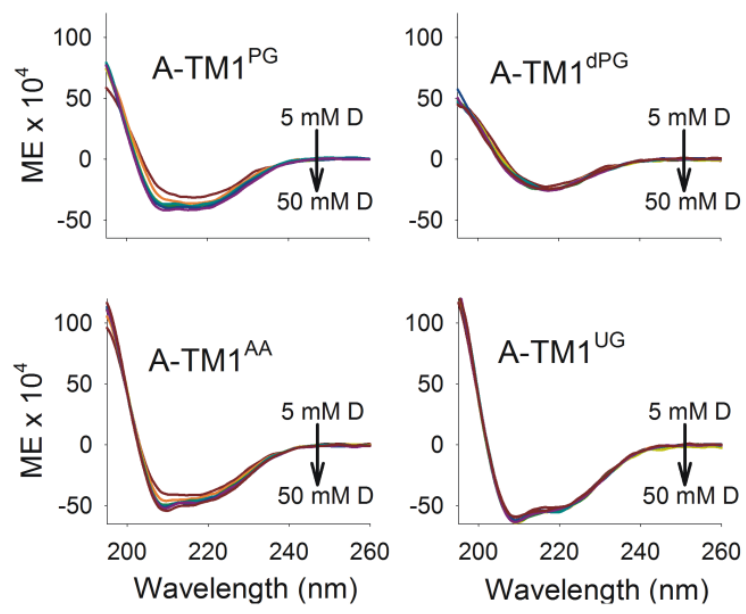

$\mathrm{D}$
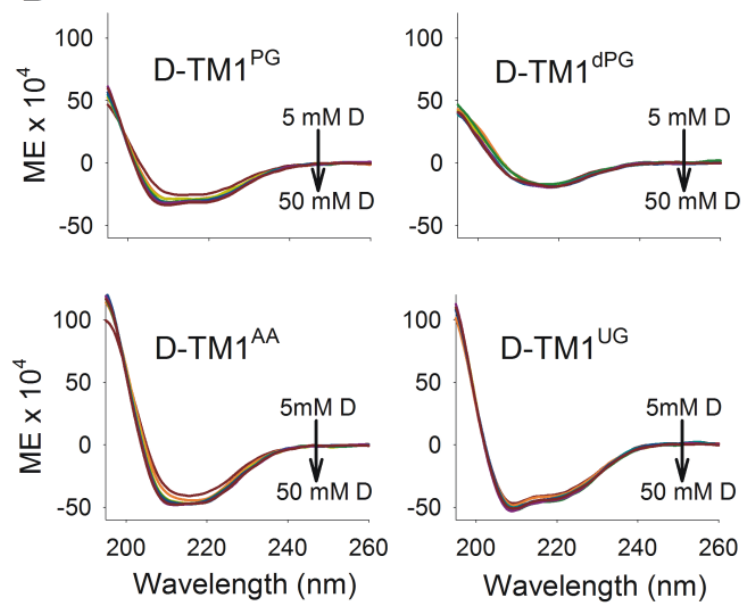

Figure S4: Far-UV CD measurements of labeled peptides across various DPRs of LDAO and DPC. (A and B) Shown are the changes in CD spectra for the four peptides labeled with Alexa Fluor ${ }^{\circledR} 350\left(\mathrm{~A}-\mathrm{TM} 1^{\mathrm{PG}}, \mathrm{A}-\mathrm{TM} 1^{\mathrm{dPG}}, \mathrm{A}-\mathrm{TM} 1^{\mathrm{AA}}\right.$ and $\left.\mathrm{A}-\mathrm{TM} 1^{\mathrm{UG}}\right)$ as the detergent concentrations are varied from $4 \mathrm{mM}$ LDAO to $100 \mathrm{mM}$ LDAO and $5 \mathrm{mM}$ DPC to $50 \mathrm{mM}$ DPC. (C and D) CD spectra of all four peptides labeled with dansyl chloride (D-TM1 ${ }^{\mathrm{PG}}$, D$\mathrm{TM} 1^{\mathrm{dPG}}$, D-TM1 ${ }^{\mathrm{AA}}$ and D-TM1 ${ }^{\mathrm{UG}}$ ) and refolded in various final LDAO concentrations (panel C) or DPC concentrations (panel D) are also provided. Note that the change in secondary structure is consistent with results from unlabeled peptides (summarized in Figure S5), suggesting that $\mathrm{N}$-terminal labeling does not alter the secondary structure of these peptide molecules. Mean residue ellipticity at $5{ }^{\circ} \mathrm{C}$ for the $\beta$-hairpin at $[\theta]_{215}=-6036.47$, and for $\alpha$ helix at $[\theta]_{208}=-20495.2$. ME: molar ellipticity in units of deg $\mathrm{cm}^{2} \mathrm{dmol}^{-1}$ and MRE: $\operatorname{deg} \mathrm{cm}^{2}$ $\mathrm{dmol}^{-1} \mathrm{res}^{-1}$. 
A

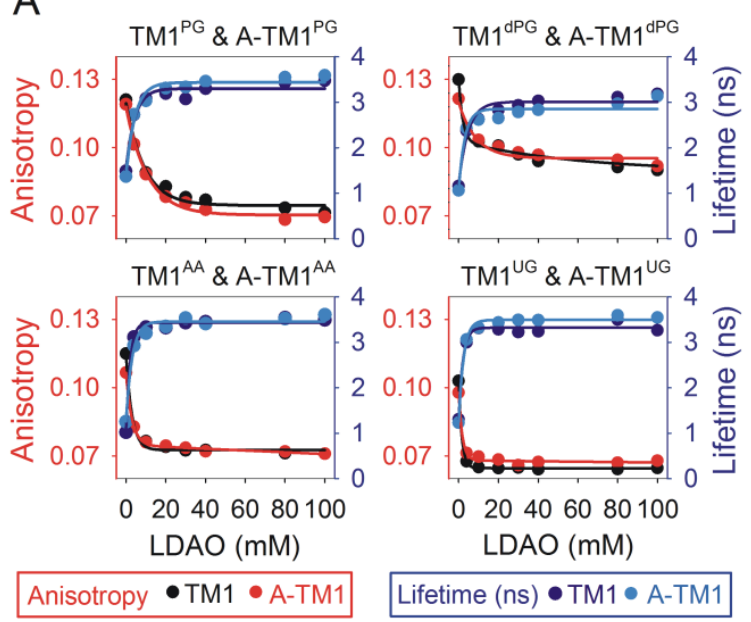

C
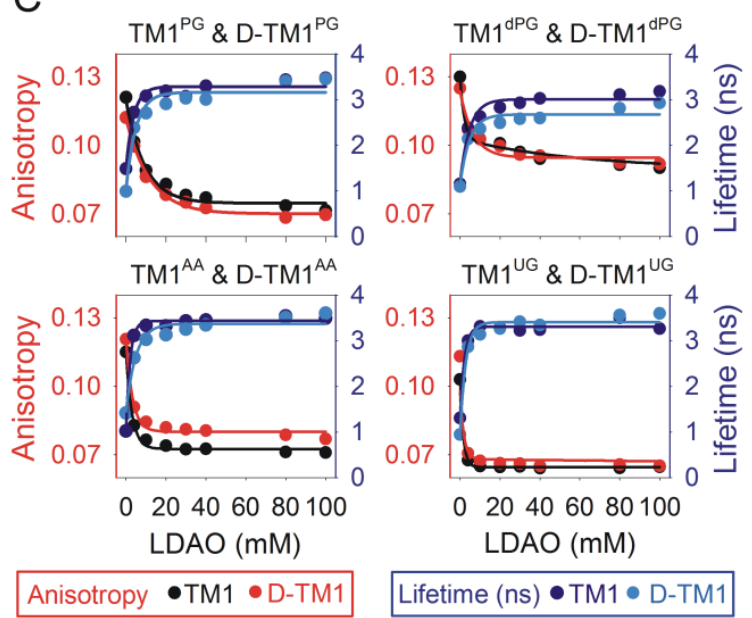

B

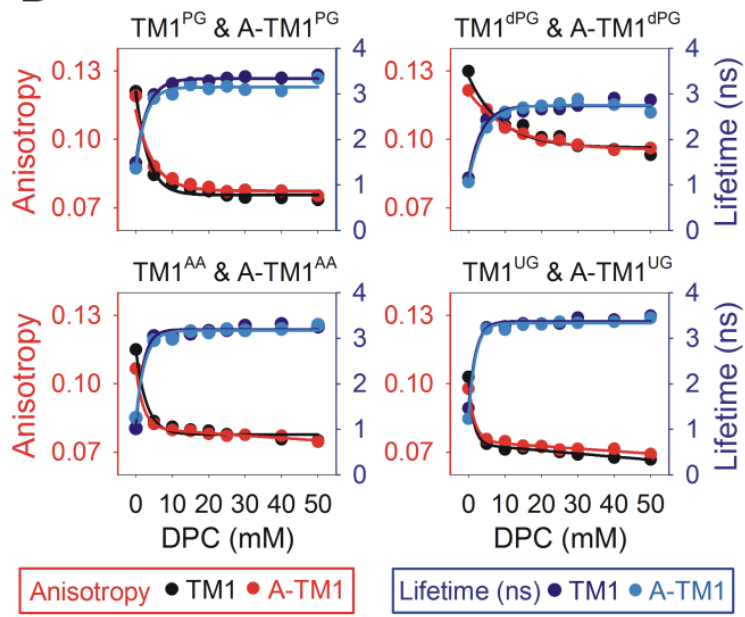

$\mathrm{D}$

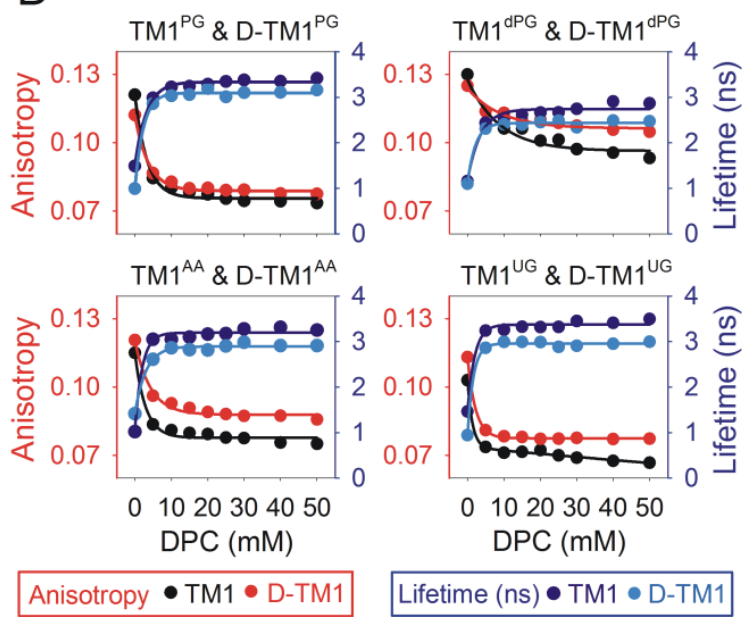

Figure S5: Influence of labeling on the anisotropy and lifetimes of peptides. Shown is the comparison of anisotropy (black - unlabeled peptide; red - labeled peptide) and lifetimes (dark blue - unlabeled peptide; light blue - labeled peptide) with increasing detergent concentration and across the four peptide sequences (TM1 variants) described in this study. (A and B) Alexa Fluor ${ }^{\circledR} 350$ labeled peptides $\left(\mathrm{A}-\mathrm{TM} 1^{\mathrm{PG}}, \mathrm{A}-\mathrm{TM} 1^{\mathrm{dPG}}, \mathrm{A}-\mathrm{TM} 1^{\mathrm{AA}}\right.$ and A$\mathrm{TM} 1^{\mathrm{UG}}$ ) in varying LDAO concentrations (4 mM LDAO - $100 \mathrm{mM}$ LDAO) and DPC concentrations (5 mM DPC - $50 \mathrm{mM}$ DPC). (C and D) Dansyl chloride labeled peptides (D$\mathrm{TM} 1^{\mathrm{PG}}, \mathrm{D}-\mathrm{TM} 1^{\mathrm{dPG}}, \mathrm{D}-\mathrm{TM} 1^{\mathrm{AA}}$ and $\mathrm{D}-\mathrm{TM} 1^{\mathrm{UG}}$ ) recorded in various concentrations of LDAO (4 mM LDAO - $100 \mathrm{mM}$ LDAO; panel B) and DPC (5 mM DPC - $50 \mathrm{mM} \mathrm{DPC}$; panel C). Unlike the absence of change in secondary structure content upon labeling with dansyl chloride (see Figure S4C), we observe that the anisotropy and lifetime values are affected in the case of D-TM1 ${ }^{\mathrm{AA}}$. This is examined further in Figure S7. However, the overall trends in the datasets are similar, allowing us to draw meaningful conclusions on the behavior of these peptides. Solid lines are fits to exponential functions and are provided to merely guide the eye. The $0 \mathrm{mM}$ data was recorded from peptide suspended in phosphate buffer. 
A

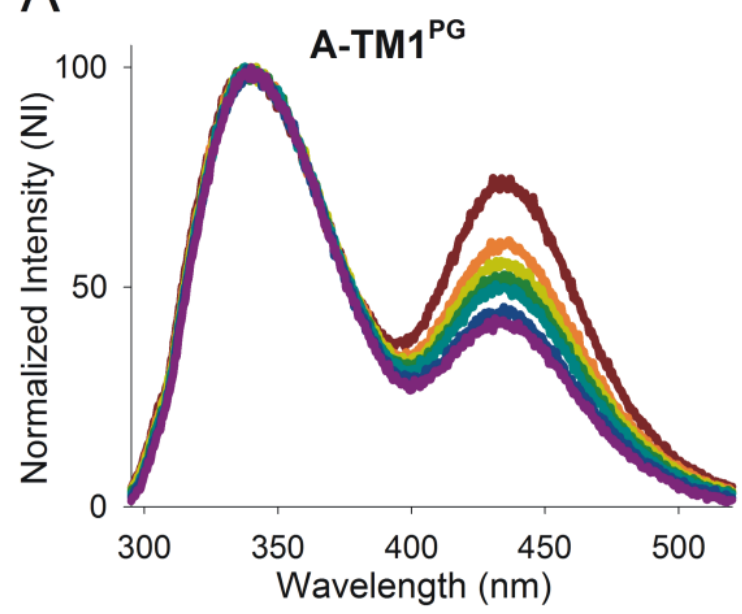

B

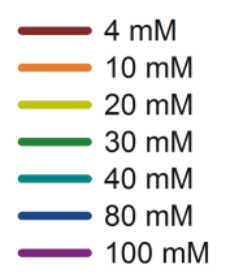

C

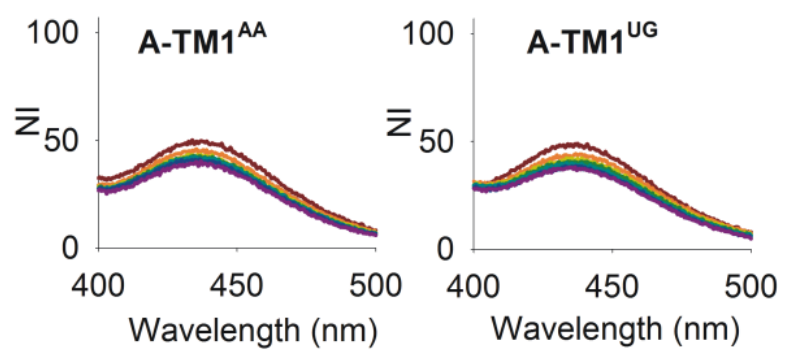

E

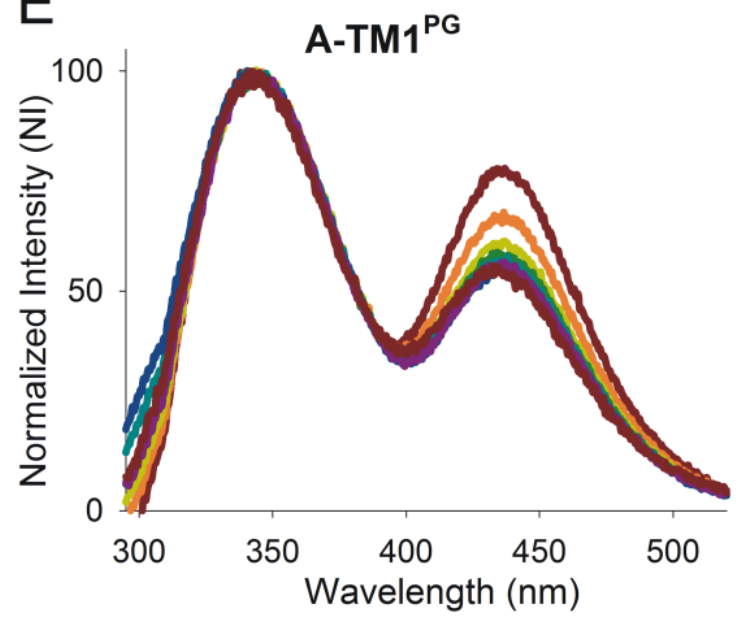

$\mathrm{F}$
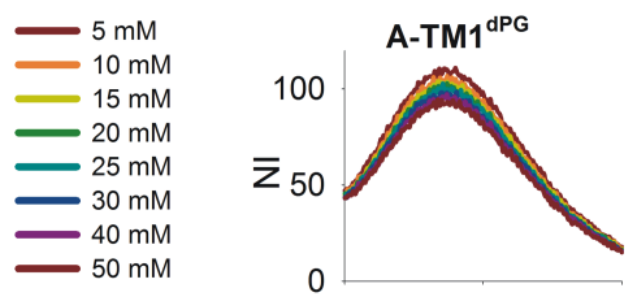

$\mathrm{H}$

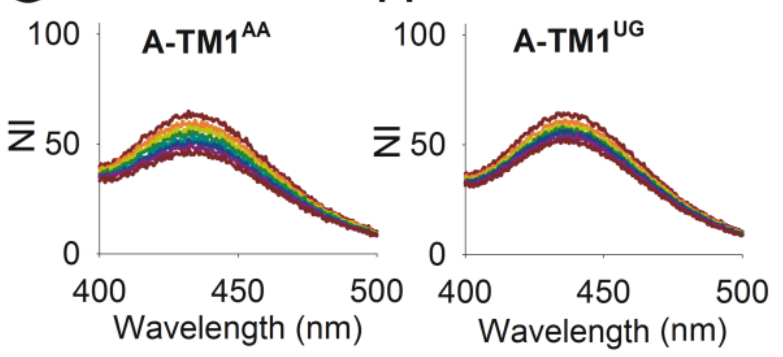

Figure S6a: Increase in Alexa Fluor ${ }^{\circledR} 350$ fluorescence in A-TM1 ${ }^{\mathrm{PG}}$ with change in LDAO (left; A-D) and DPC (right; E-H) concentrations. The acceptor fluorescence intensity is normalized against the respective $\operatorname{Trp}$ (donor) fluorescence. A-TM1 ${ }^{\mathrm{dPG}}(\mathrm{B}, \mathrm{F})$ shows the highest FRET efficiency owing to its $\beta$-hairpin structure. The increase in FRET efficiency in $\mathrm{A}-\mathrm{TM} 1^{\mathrm{AA}}(\mathrm{C}, \mathrm{G})$ and $\mathrm{A}-\mathrm{TM} 1^{\mathrm{UG}}(\mathrm{D}, \mathrm{H})$ is negligible. A-TM1 ${ }^{\mathrm{PG}}(\mathrm{A}, \mathrm{E})$ shows a DPRdependent FRET efficiency, as it alters its conformation from a helical structure in high DPR (low FRET) to a $\beta$-hairpin structure in low DPR (high FRET). 

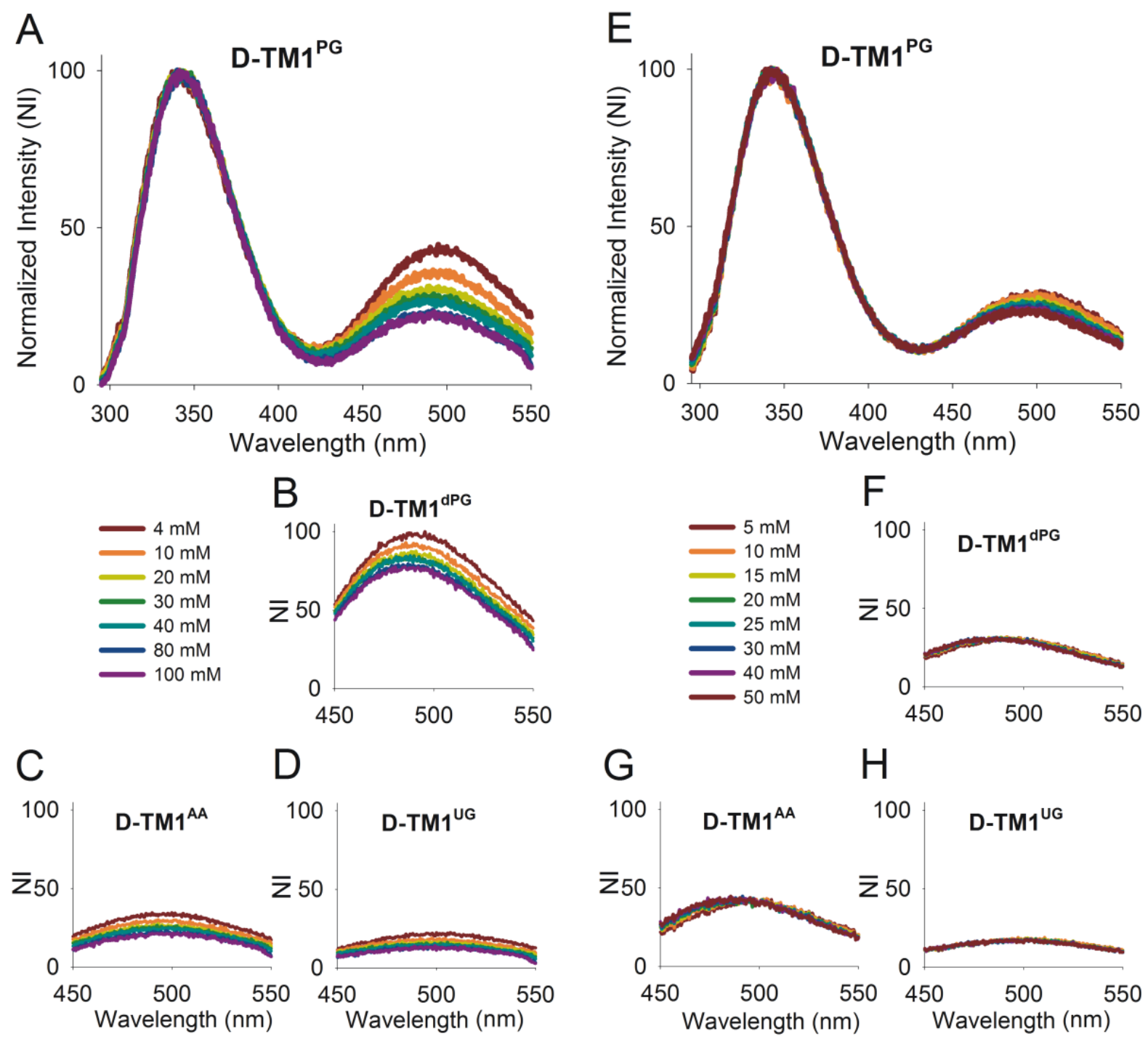

Figure S6b: Increase in dansyl chloride fluorescence in $\mathrm{D}-\mathrm{TM} 1^{\mathrm{PG}}$ with change in LDAO concentration (left; A-D) and DPC (right; E-H). D-TM1 ${ }^{\mathrm{dPG}}$ (B) shows the highest FRET efficiency owing to its $\beta$-hairpin structure. The increase in FRET efficiency in D-TM1 ${ }^{\mathrm{AA}}(\mathrm{C})$ and D-TM1 ${ }^{\mathrm{UG}}(\mathrm{D})$ is negligible. D-TM1 ${ }^{\mathrm{PG}}$ (A) shows a DPR-dependent FRET efficiency, as it alters its conformation from a helical structure in high DPR (low FRET) to a $\beta$-hairpin structure in low DPR (high FRET). (Right) The change in FRET efficiency is only marginal in $\mathrm{D}-\mathrm{TM} 1^{\mathrm{PG}}(\mathrm{E})$ in DPC micelles, and is negligible in all other peptides $(\mathrm{F}-\mathrm{H})$. Since we observe structural conversion in $\mathrm{D}-\mathrm{TM} 1^{\mathrm{PG}}$ and can confidently determine the secondary structure of the other three peptides with varying DPC concentration, it is surprising that we are unable to detect significant FRET in this condition. Indeed, careful evaluation of the spectra clearly reveals that the acceptor fluorophore demonstrates a change in the emission wavelength, instead of the canonical change in intensity observed in all other instances. This is examined further in Figure S7. In all spectra, the acceptor fluorescence intensity is normalized against the respective $\operatorname{Trp}$ (donor) fluorescence. 

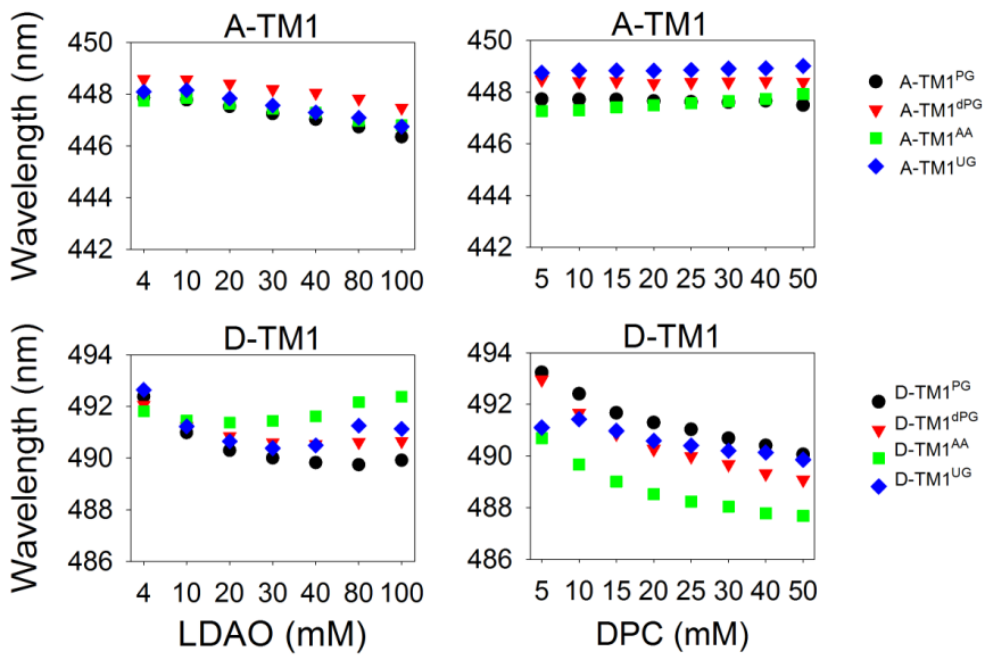

Figure S7: Change in the average emission wavelength $(\langle\lambda\rangle)$ of the FRET acceptor Alexa Fluor ${ }^{\circledR} 350$ (top panels) or dansyl chloride (bottom panels) across all peptides in varying concentrations of LDAO (left panels) or DPC (right panels). Note how the $\langle\lambda\rangle$ does not change considerably across all four peptides in both LDAO and DPC for Alexa Fluor ${ }^{\circledR} 350-$ labeled peptides and for LDAO in the dansyl chloride - labeled peptides. However, the change manifests itself in the form of acceptor fluorescence intensity, as demonstrated in Figure S6. In the case of dansyl chloride - labeled peptides in DPC, however, we observe a 3 $\mathrm{nm}$ difference in $\langle\lambda\rangle$ for D-TM1 ${ }^{\mathrm{PG}}$ and D-TM $1^{\mathrm{dPG}}$. Further, D-TM1 ${ }^{\mathrm{AA}}$ shows a $3 \mathrm{~nm}$ shift from low to high DPC concentrations. A blue shift in $\langle\lambda\rangle$ without considerable change in fluorescence intensity can occur if the acceptor molecule becomes increasingly rigid upon increase in DPC concentration. The higher anisotropy values along with the increase in lifetimes, particularly in the case of D-TM1 ${ }^{\mathrm{AA}}$ (see Figure S5) support this conclusion. 

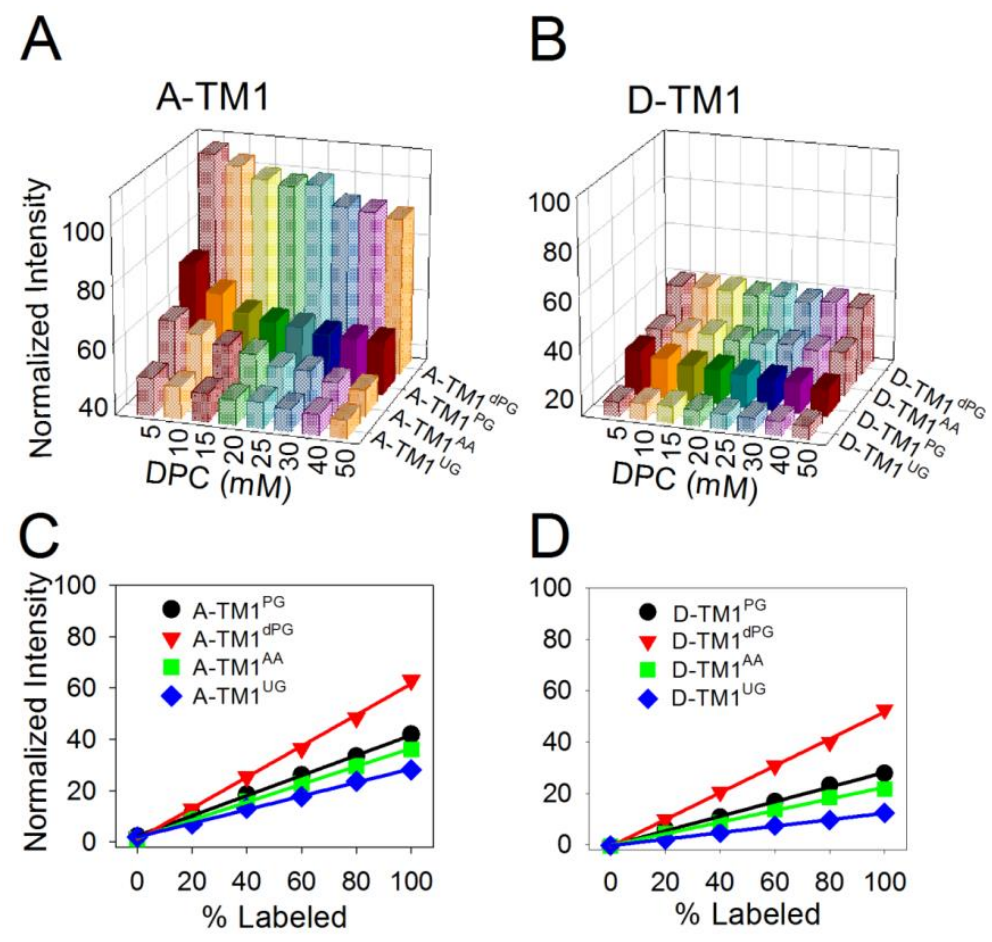

Figure S8 (continued from Figure 2 of the main text): (A and B) Summary of the dependence of acceptor fluorescence (Alexa Fluor ${ }^{\circledR} 350$, panel A; dansyl chloride, panel B) across the four peptides, with increasing DPC concentration. Note how the highest FRET is observed in A-TM $1^{\mathrm{dPG}}$, which retains a $\beta$-sheet structure across all DPRs. FRET efficiency is lowest for A-TM1 ${ }^{\mathrm{AA}}$ and A-TM1 ${ }^{\mathrm{UG}}$ in Alexa Fluor ${ }^{\circledR} 350$ - labeled peptides. The high FRET efficiency in $\mathrm{D}-\mathrm{TM} 1^{\mathrm{AA}}$ is due to the partial fluorophore rigidity, as explained in Figure S7; however, this does not exhibit a change in intensity with increasing DPC concentration. Only A-TM1 ${ }^{\text {PG }}$ shows an increase in FRET efficiency as the peptide undergoes alteration from a helical structure in high DPC concentration $(50 \mathrm{mM})$ to a $\beta$-hairpin form in low $(5 \mathrm{mM})$ DPC. Note how the change in FRET efficiency of labeled TM1 ${ }^{\mathrm{PG}}$ occurs at a narrow DPC concentration, as compared with LDAO (shown in Figure 2C-D of the main text). This is in good agreement with the DPR dependence of the conformational interconversion of TM1 ${ }^{\mathrm{PG}}$ observed in both LDAO and DPC, using far-UV CD. (C and D) Linear dependence of FRET efficiency to the concentration of labeled peptide (Alexa Fluor® 350, panel C; dansyl chloride, panel D) in $100 \mathrm{mM}$ LDAO, suggesting that the observed FRET is not a result of peptide aggregation. 

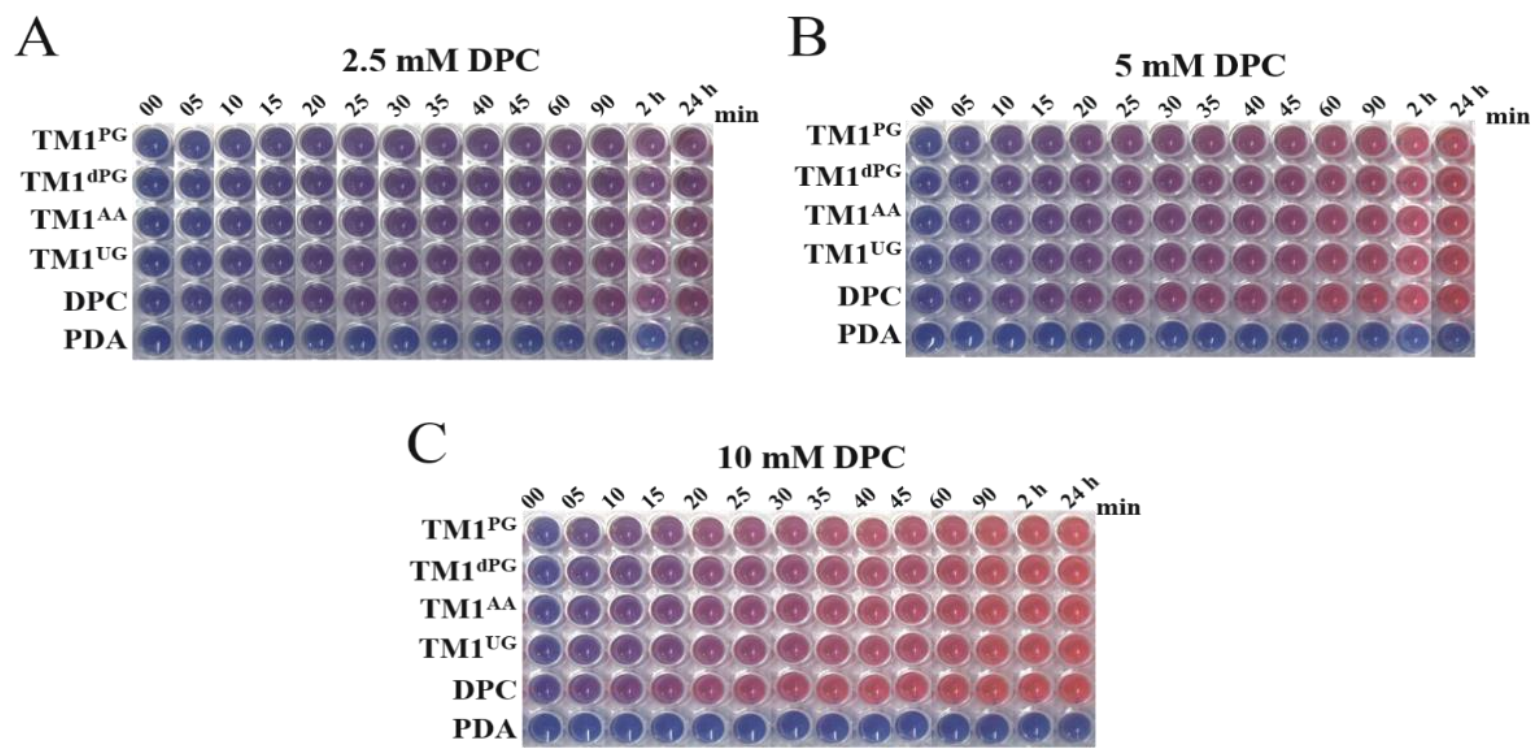

Figure S9a: Colorimetric assay of peptide-membrane association using $1.0 \mathrm{mM}$ PDA vesicles. Shown here are representative plate profiles obtained from a single experiment. Note that the images captured for various time points are shown together for convenient presentation. Empty PDA vesicles are blue in color (last row in each array shown here) and show progressive transformation into red vesicles upon addition of DPC (penultimate row in each array). The rate of this conversion is directly dependent on the concentration of DPC added (compare across A, B and C). Addition of the peptide alters DPC-PDA interaction, slowing the red color development rates in these samples. Shown here are representative results of colorimetric assays performed with the four peptides $\left(\mathrm{TM} 1^{\mathrm{PG}}, \mathrm{TM} 1^{\mathrm{dPG}}, \mathrm{TM} 1^{\mathrm{AA}}\right.$, $\mathrm{TM} 1^{\mathrm{UG}}$ ) in $2.5 \mathrm{mM}$ DPC (panel A), $5.0 \mathrm{mM}$ (panel B) and 10.0 mM DPC (panel C). All reactions were carried out at $25^{\circ} \mathrm{C}$ and monitored for $24 \mathrm{~h}$. 

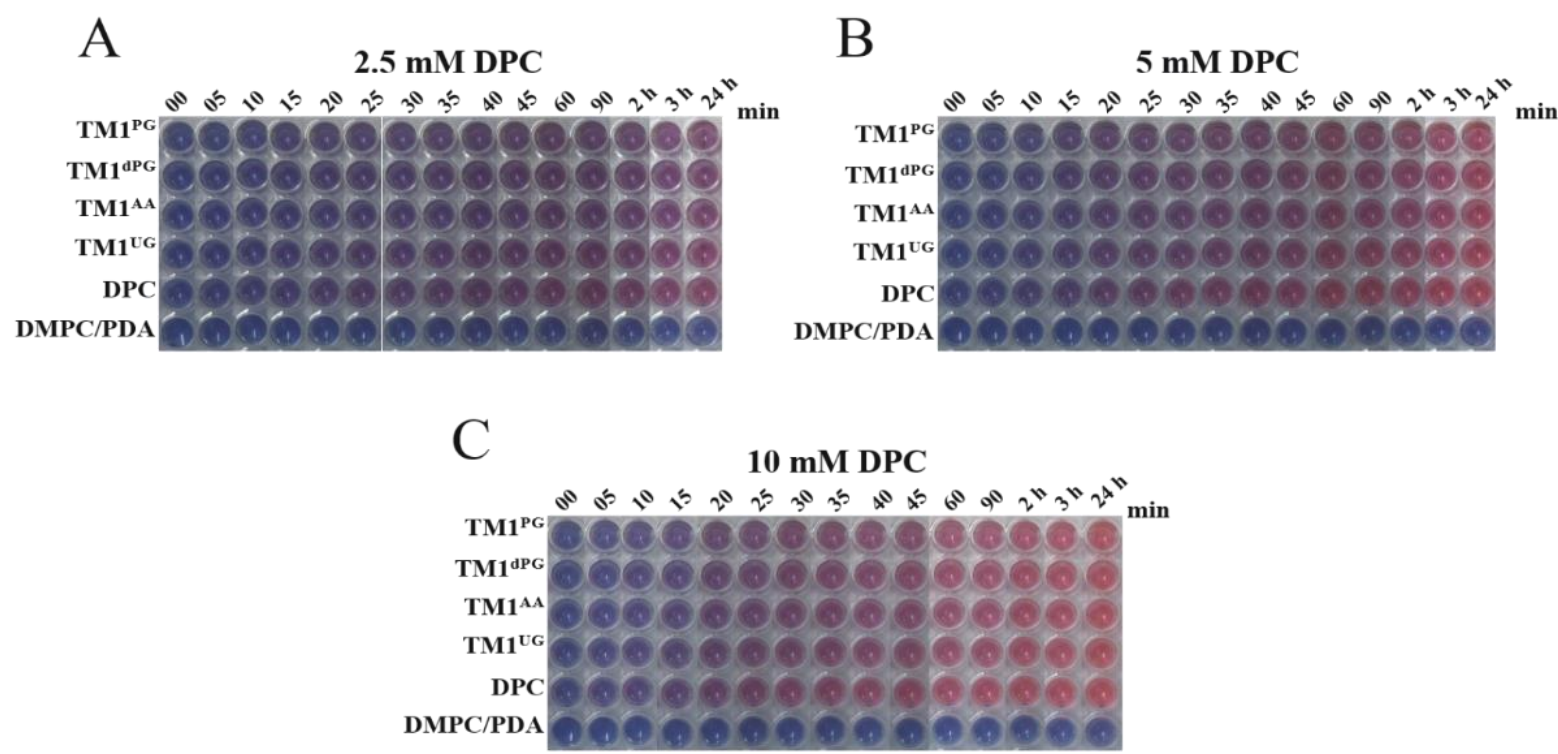

Figure S9b: Colorimetric assay of peptide-membrane association using 1.0 mM DMPC/PDA vesicles prepared in 1:3 ratio. Shown here are representative plate profiles obtained from a single experiment. Note that the images captured for various time points are shown together for convenient presentation. Empty DMPC/PDA vesicles are blue in color (last row in each array shown here) and show progressive transformation into red vesicles upon addition of DPC (penultimate row in each array). The rate of this conversion is directly dependent on the concentration of DPC added (compare across A, B and C). Addition of the peptide alters DPC-DMPC/PDA interaction, slowing the rate of red color development in these samples. Shown here are representative results of colorimetric assays performed with the four peptides $\left(\mathrm{TM} 1^{\mathrm{PG}}, \mathrm{TM} 1^{\mathrm{dPG}}, \mathrm{TM} 1^{\mathrm{AA}}, \mathrm{TM} 1^{\mathrm{UG}}\right.$ ) in $2.5 \mathrm{mM}$ DPC (panel A), $5.0 \mathrm{mM}$ (panel B) and 10.0 $\mathrm{mM}$ DPC (panel C). All reactions were carried out at $25^{\circ} \mathrm{C}$ and monitored for $24 \mathrm{~h}$. 

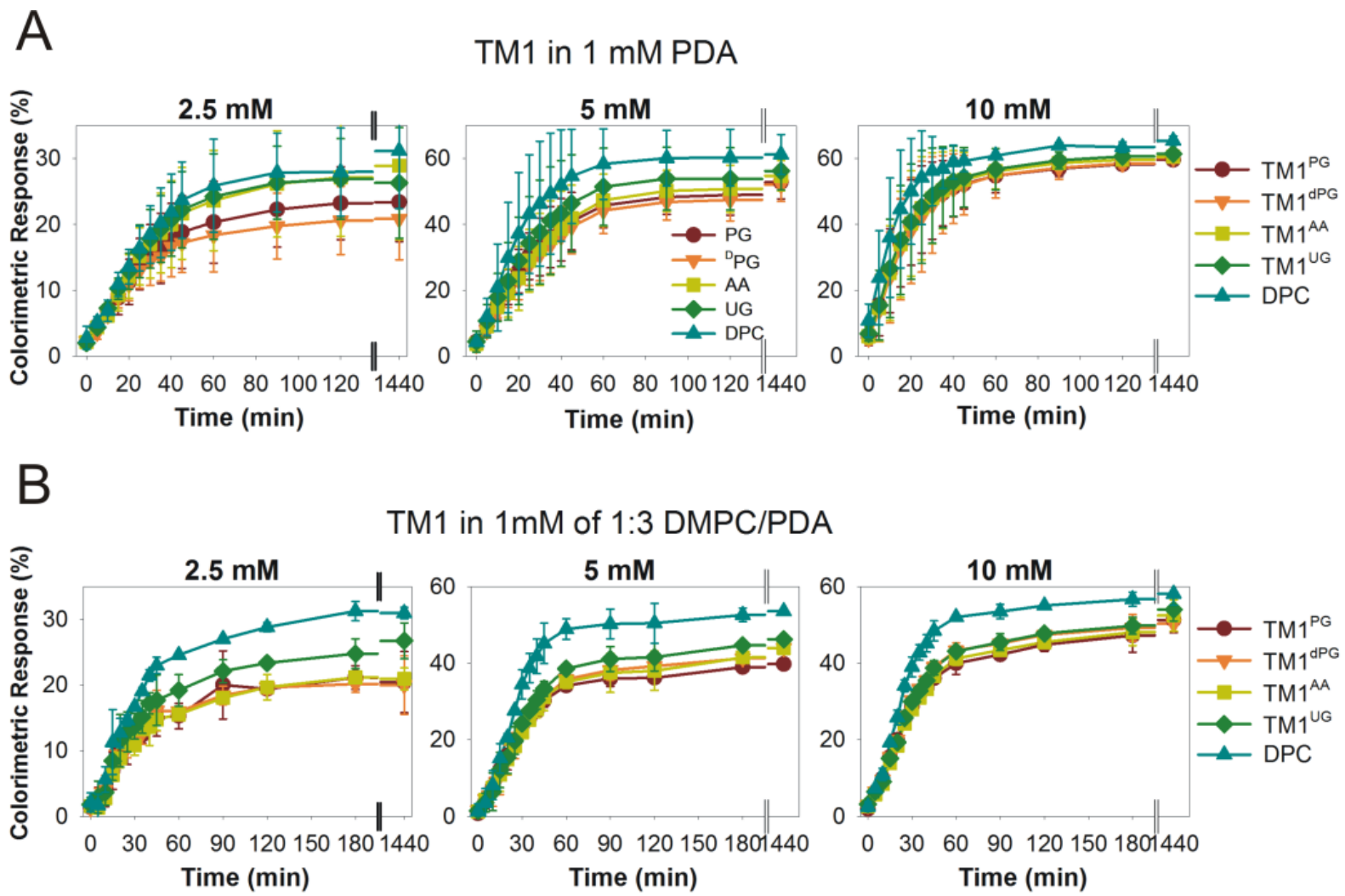

Figure S9c: Summary of the percent change in colorimetric response calculated as a ratio of intensities at $520 \mathrm{~nm}$ and $640 \mathrm{~nm}$, obtained in the absorbance spectra in PDA (A) and DMPC/PDA (B). All data are averaged over two independent experiments. The colorimetric response obtained depends on the efficiency of cross linking of 10, 12-tricosadiynoic acid upon UV irradiation, and varies across different preparations. Hence, the recorded response percentage is different across independent experiments, giving rise to high values of error bars in some cases. However, in all our data, the helical peptides show a marginally faster change in response units compared to the $\beta$-hairpins; this difference is consistent across the independent experiments. 
Anisotropy of TM1 vs time monitored in PDA vesicles

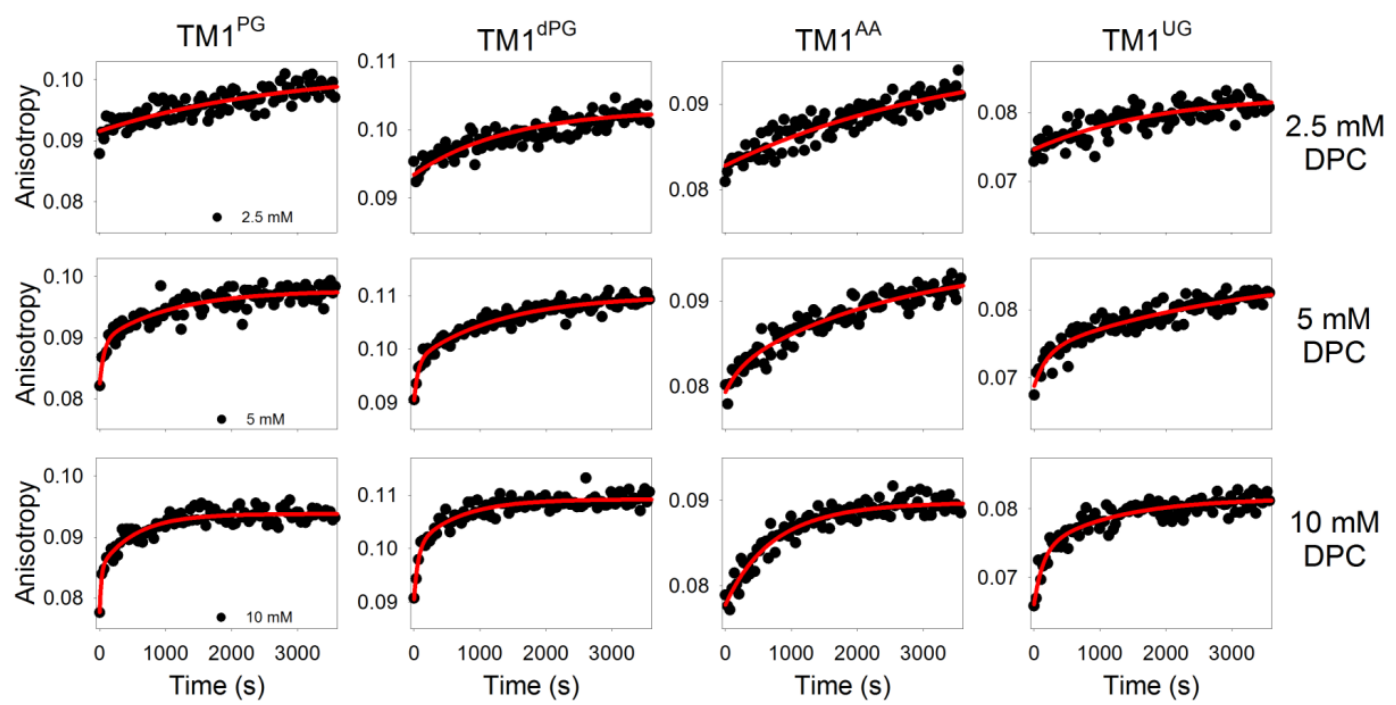

Figure S10a: Change in Trp anisotropy monitored at $345 \mathrm{~nm}$, immediately after peptide addition into $1.0 \mathrm{mM}$ PDA vesicles. Shown across the various rows is the anisotropy change observed for the four peptides. Shown across the different columns is the dependence of the rate of anisotropy change when each peptide is prepared in $2.5 \mathrm{mM}, 5.0 \mathrm{mM}$ or $10.0 \mathrm{mM}$ DPC. At low DPC concentrations, the anisotropy change for all peptides can be described by a single exponential function. However, as the DPC concentration increases, the graphs fit better to a double exponential function, suggesting the occurrence of two phenomena with different rate functions - a rapid peptide adsorption followed by a slower association rate with PDA. 
Anisotropy of TM1 vs time monitored in 1:3 DMPC/PDA vesicles

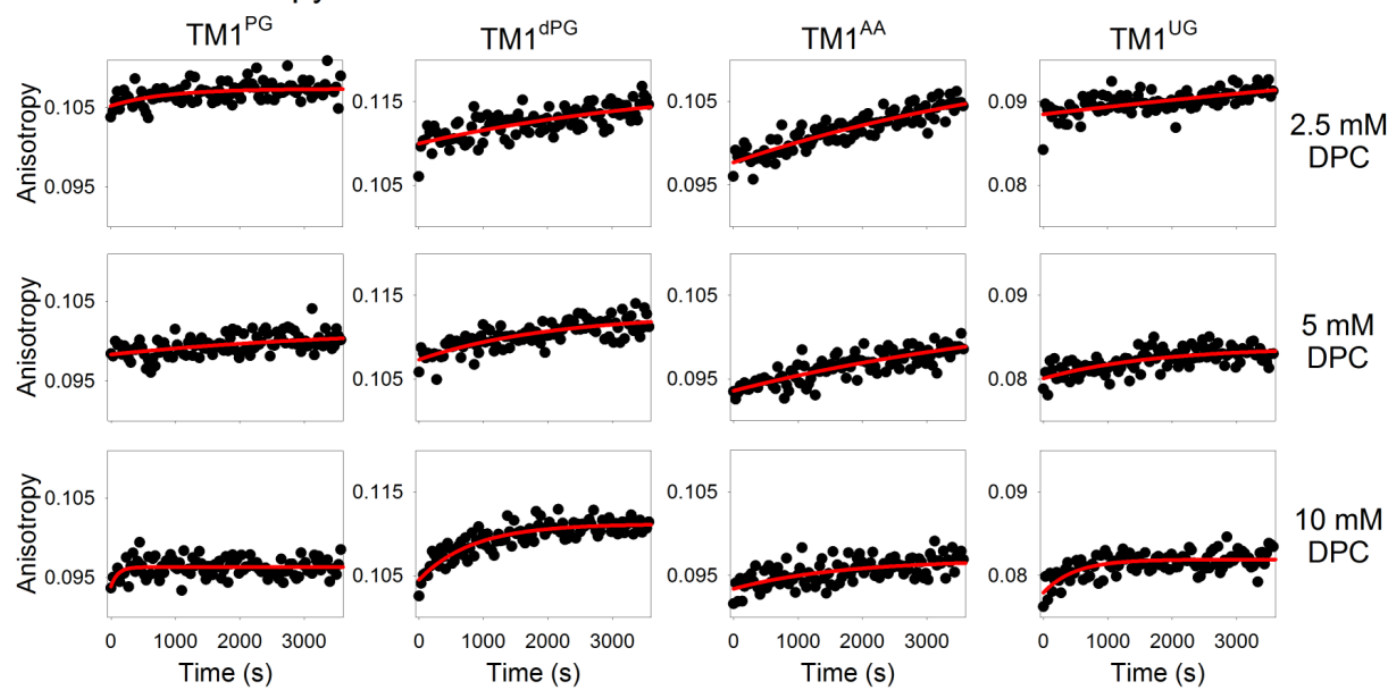

Figure S10b: Change in Trp anisotropy monitored at $345 \mathrm{~nm}$, immediately after peptide addition into $1.0 \mathrm{mM}$ DMPC/PDA vesicles prepared in a 1:3 ratio. Shown across the various rows is the anisotropy change observed for the four peptides. Shown across the different columns is the dependence of the rate of anisotropy change when each peptide is prepared in $2.5 \mathrm{mM}, 5.0 \mathrm{mM}$ or $10.0 \mathrm{mM}$ DPC. Unlike the change in the association mechanism in PDA vesicles upon increasing the DPC concentration, in DMPC/PDA vesicles, all peptides exhibit a single association rate, except for $\mathrm{TM}^{\mathrm{dPG}}$; the latter shows a clear change to a double exponent in $10 \mathrm{mM}$ DPC. This suggests that in vivo, TM1 association with the bacterial inner membrane is likely to proceed through a helical structure. Conformational interconversion therefore occurs in membrana. 

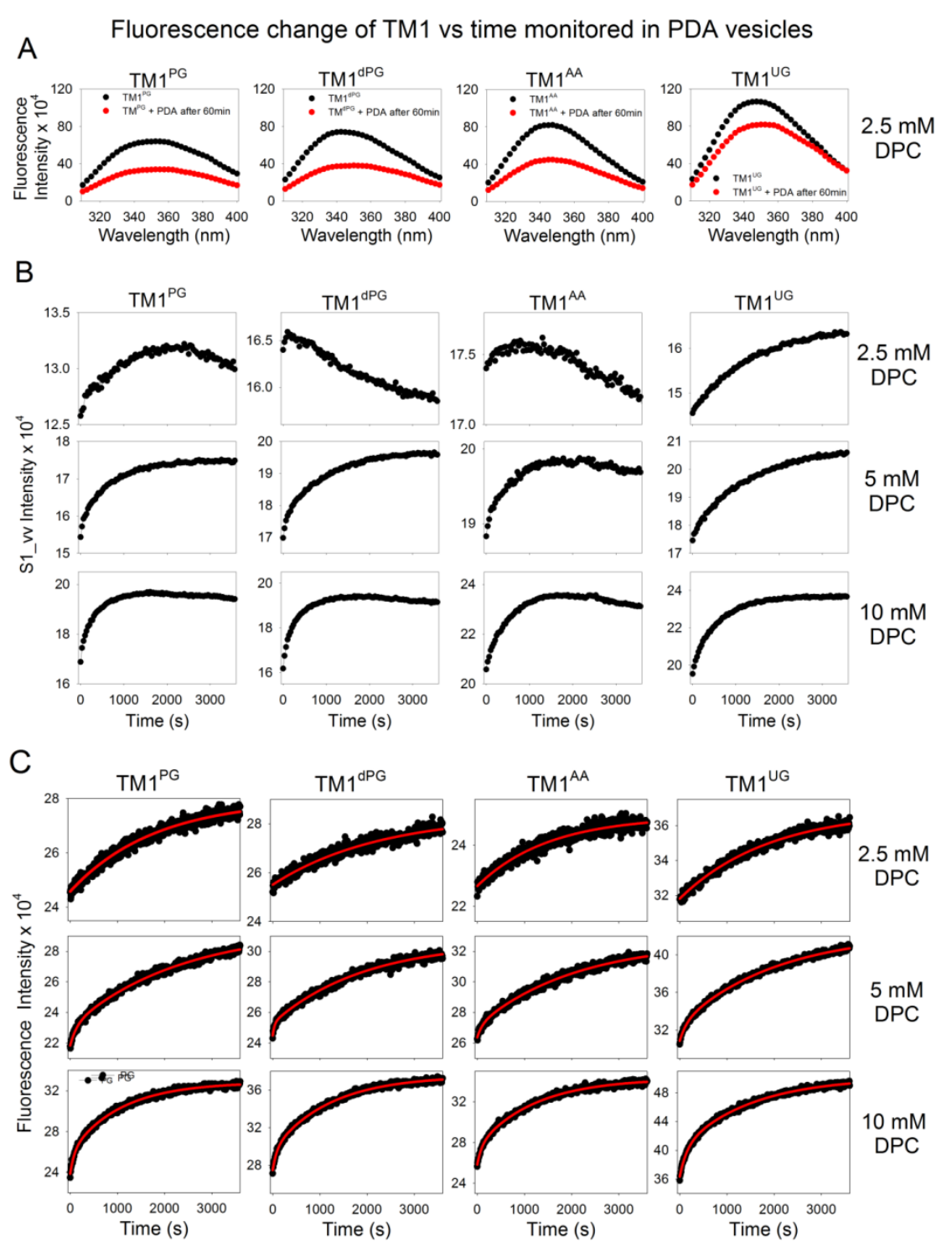

Figure S11a: Monitoring changes in peptide Trp fluorescence upon association with PDA vesicles. (A) Representative fluorescence spectra (in arbitrary units) of TM1 (TM1 ${ }^{\mathrm{PG}}$, $\mathrm{TM} 1^{\mathrm{dPG}}, \mathrm{TM} 1^{\mathrm{AA}}, \mathrm{TM}^{\mathrm{UG}}$ ) in $2.5 \mathrm{mM}$ DPC before (black circles) and after 60 min of peptide addition to PDA vesicles (red circles). (B-C) Change in Trp fluorescence (S1_vv intensity and total fluorescence) was monitored at $345 \mathrm{~nm}$ immediately after peptide addition into 1.0 mM PDA vesicles (the corresponding anisotropy measurements are shown in Figure S10a). Shown across the different columns is the dependence of the rate of fluorescence change when each peptide is prepared in $2.5 \mathrm{mM}, 5.0 \mathrm{mM}$ or $10.0 \mathrm{mM}$ DPC. The observed increase in fluorescence intensity directly correlates with the formation of a stable (rigid and/or buried) Trp environment upon interaction with PDA vesicles. 
Fluorescence change of TM1 vs time monitored in 1:3 DMPC/PDA vesicles A
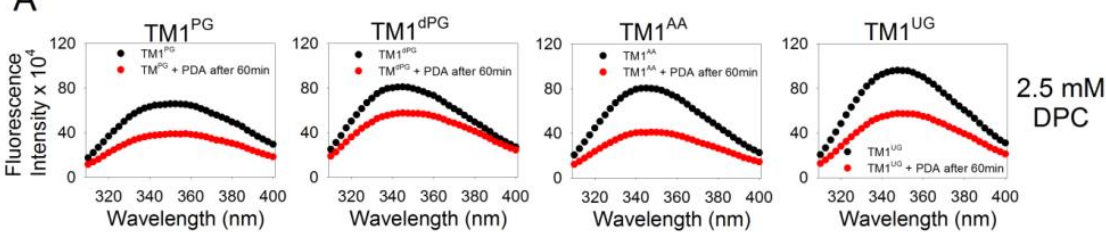

B
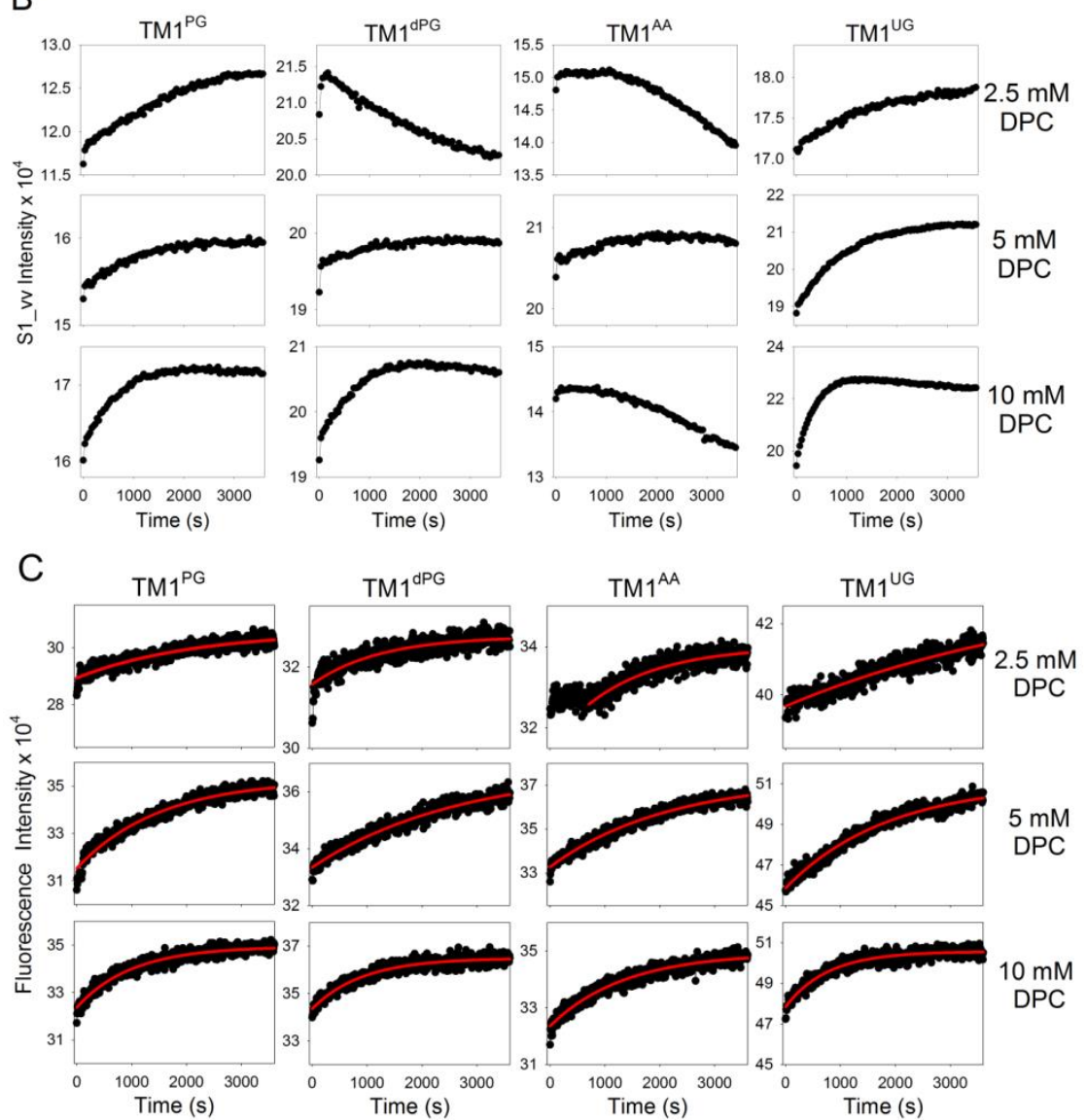

Figure S11b: Monitoring changes in peptide Trp fluorescence upon association with 1:3 DMPC/PDA vesicles. (A) Representative fluorescence spectra (in arbitrary units) of TM1 $\left(\mathrm{TM} 1^{\mathrm{PG}}, \mathrm{TM} 1^{\mathrm{dPG}}, \mathrm{TM} 1^{\mathrm{AA}}, \mathrm{TM} 1^{\mathrm{UG}}\right)$ in $2.5 \mathrm{mM}$ DPC before (black circles) and after $60 \mathrm{~min}$ of peptide addition to DMPC/PDA vesicles (red circles). (B-C) Change in Trp fluorescence (S1_vv intensity and fluorescence) was monitored at $345 \mathrm{~nm}$ immediately after peptide addition into $1.0 \mathrm{mM}$ DMPC/PDA vesicles (the corresponding anisotropy measurements are shown in Figure S10b). Shown across the different columns is the dependence of the rate of fluorescence change when each peptide is prepared in $2.5 \mathrm{mM}, 5.0 \mathrm{mM}$ or $10.0 \mathrm{mM}$ DPC. The observed increase in fluorescence intensity directly correlates with the formation of a stable (rigid and/or buried) Trp environment, upon interaction with DMPC/PDA vesicles. 

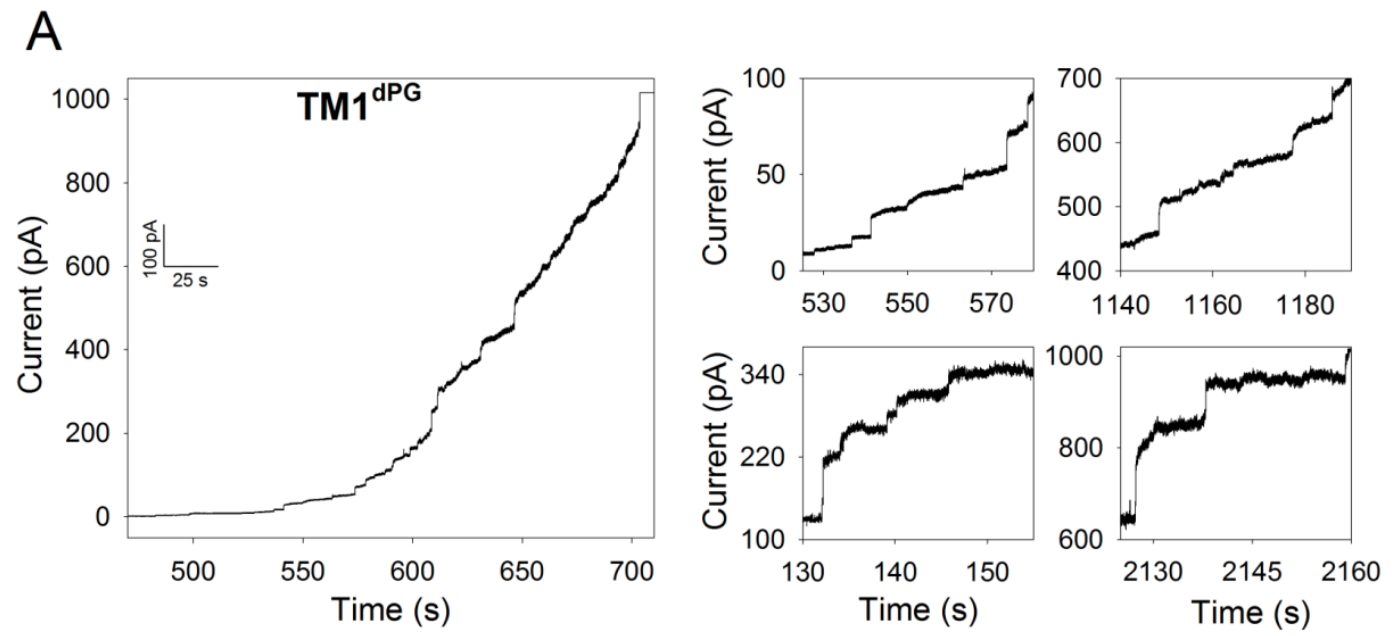

B
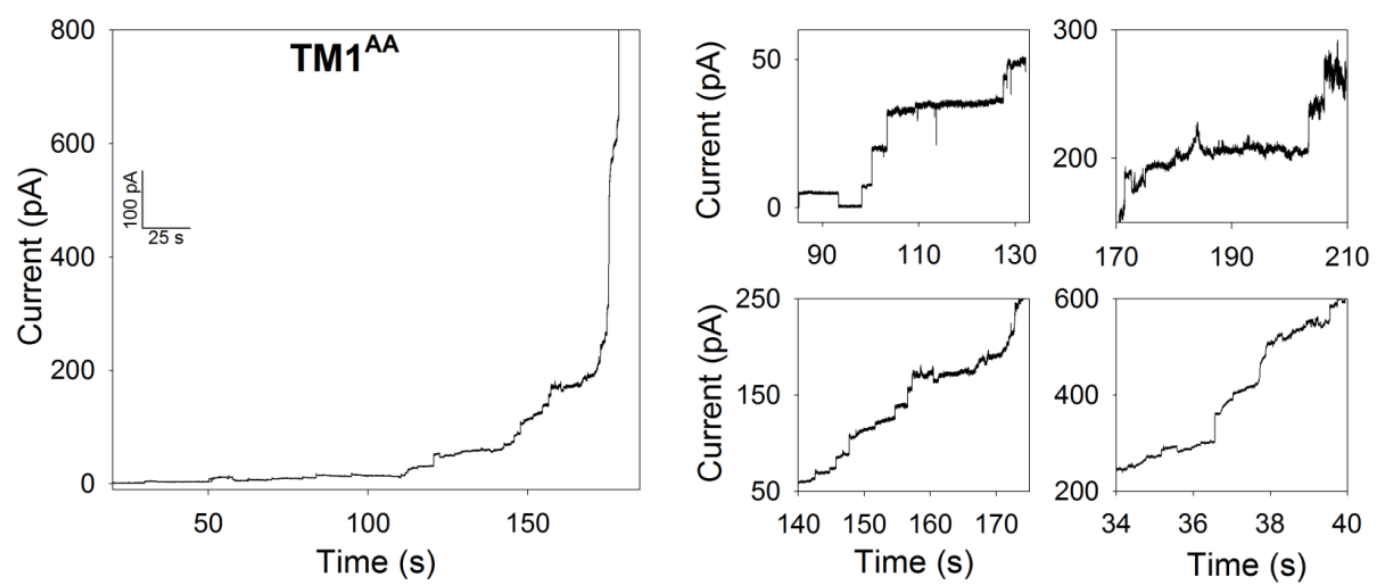

C
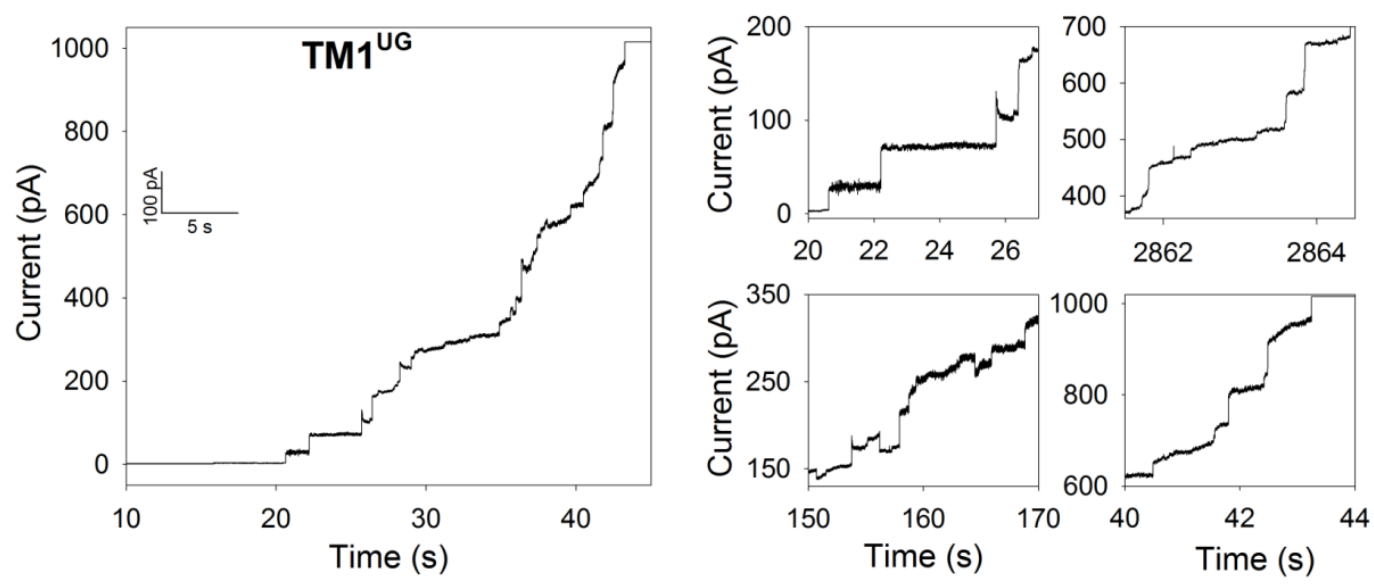

Figure S12: Representative planar lipid bilayer measurements for membrane association and pore formation by $\mathrm{TM}^{\mathrm{dPG}}(\mathrm{A}), \mathrm{TM}^{\mathrm{AA}}(\mathrm{B})$ and $\mathrm{TM} 1^{\mathrm{UG}}(\mathrm{C})$ in DiPhPC membranes. As shown in Figure 4B-C, representative magnifications of different segments of the recordings are also provided, as the current increases from $0 \mathrm{pA}$ to $1000 \mathrm{pA}$, in various step sizes, in a peptide-dependent manner. In all experiments, the applied voltage was maintained at $10 \mathrm{mV}$. Though the secondary structures vary between $\mathrm{TM} 1^{\mathrm{dPG}}$ ( $\beta$-hairpin) and $\mathrm{TM} 1^{\mathrm{UG}}$ (helix), both peptides show pore-forming activity. This led us to conclude that both the secondary structures can display holin-like characteristics. 

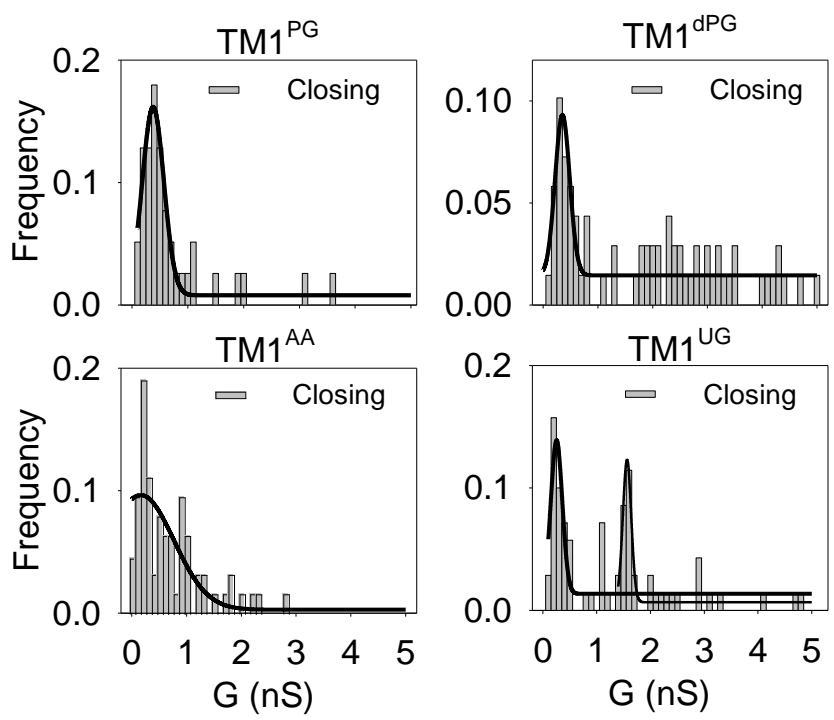

Figure S13: Closing events of TM1. In addition to peptide oligomerization in the membrane, we also obtain dissociation events that mimic pore closing behavior and manifest themselves in the form of a reduction in the measured current. Such occurrences have been converted to conductance (units of $\mathrm{nS}$ ) in this figure, for all four peptides. A single abundant pore closing size was preferentially observed for all peptides except TM1 ${ }^{\mathrm{UG}}$. Pore closing occurred with conductance values of $0.4 \mathrm{nS}$ for TM1 ${ }^{\mathrm{PG}}, 0.3 \mathrm{nS}$ for TM1 $1^{\mathrm{dPG}}, 0.2 \mathrm{nS}$ for TM1 ${ }^{\mathrm{AA}}$ and with 0.2 $\mathrm{nS}$ and $1.6 \mathrm{nS}$ for $\mathrm{TM}^{\mathrm{UG}}$. The applied voltage was maintained at $10 \mathrm{mV}$ for all experiments. When compared with the instances of pore opening (shown in Figure 4D of the main text), pore closing showed a lower frequency of occurrence. 


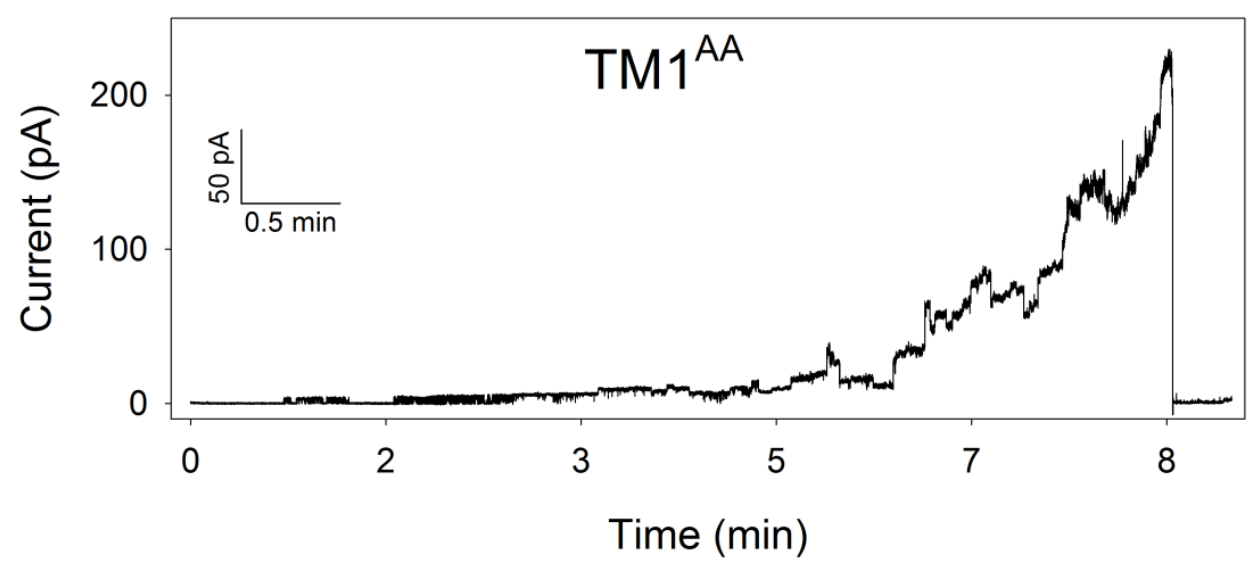

Figure S14: Representative data for $\mathrm{TM} 1^{\mathrm{AA}}$ in the presence of a $\mathrm{pH}$ gradient highlights an instance where membrane disruption is not observed. Accumulation of the TM1 ${ }^{\mathrm{AA}}$ peptide in membrana increases the observed current (see recording between 7-8 min). However, instead of complete membrane disruption and increase in current to $1000 \mathrm{pA}$, the membrane is reformed (at $8 \mathrm{~min}$ ). This, and several other planar lipid bilayer recordings showed membrane re-formation when the current reached $200 \mathrm{pA}$. It is possible that sufficient peptide association in the membrane occurs till $\sim 200 \mathrm{pA}$. At this point the system either undergoes membrane disruption by the cascading effect of rapid peptide association (as shown in Figure 5), or the membrane is re-formed (as shown in Figure 5E and here). 


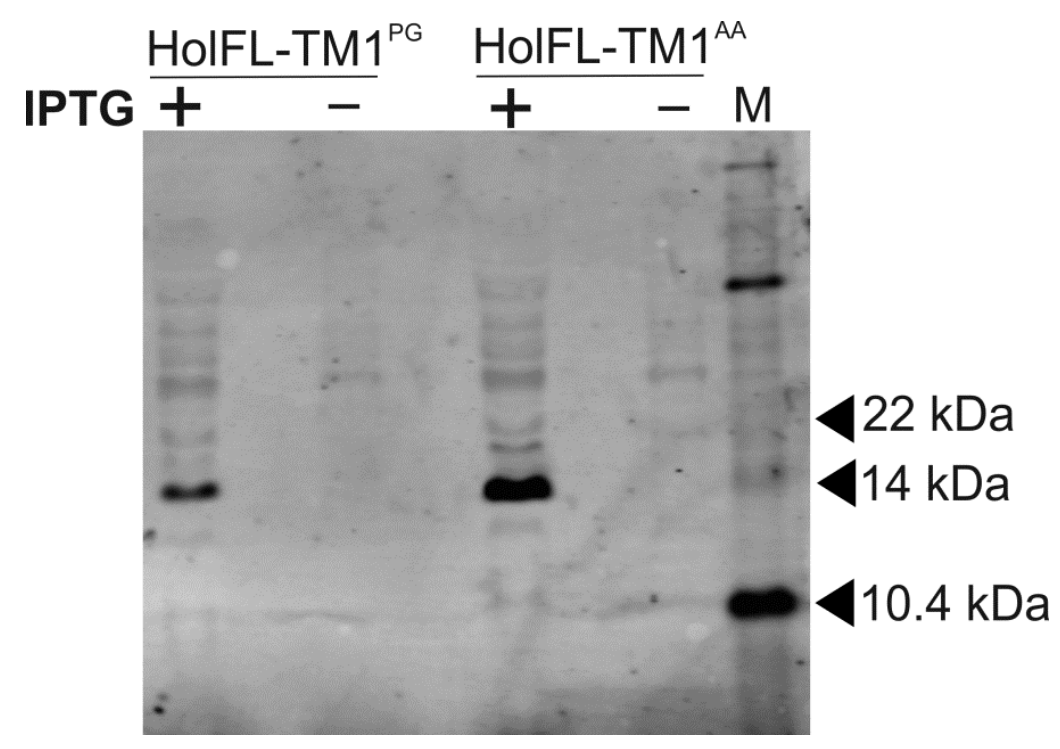

Figure S15: Western blotting analysis of the full-length holin expression in E. coli. Total cell lysate of the uninduced (-) and IPTG-induced (+) is loaded in each lane. Western blot was probed with anti-His antibodies. ' $M$ ' represents the protein molecular weight marker; three bands are labeled. The amount of HolFL-TM1 ${ }^{\mathrm{AA}}$ detected is higher than HolFL-TM1 ${ }^{\mathrm{PG}}$. This can be due to the higher toxicity of HolFL-TM1 ${ }^{\mathrm{PG}}$, which will result in fewer available cells that are processed for the immunoblotting experiment. 


\section{References}

1. Lella, M., and Mahalakshmi, R. (2013) Pro-Gly mediated conformational switch of mycobacteriophage D29 holin transmembrane domain I is lipid concentration driven, Chem. Commun. 49, 9594-9596.

2. Jonas, U., Shah, K., Norvez, S., and Charych, D. H. (1999) Reversible color switching and unusual solution polymerization of hydrazide-modified diacetylene lipids, J. Am. Chem. Soc. 121, 4580-4588.

3. Kolusheva, S., Shahal, T., and Jelinek, R. (2000) Peptide-membrane interactions studied by a new phospholipid/polydiacetylene colorimetric vesicle assay, Biochemistry 39, 15851-15859.

4. Kolusheva, S., Boyer, L., and Jelinek, R. (2000) A colorimetric assay for rapid screening of antimicrobial peptides, Nat. Biotechnol. 18, 225-227.

5. Kim, Y. R., Jung, S., Ryu, H., Yoo, Y. E., Kim, S. M., and Jeon, T. J. (2012) Synthetic biomimetic membranes and their sensor applications, Sensors 12, 95309550.

6. Yarimaga, O., Jaworski, J., Yoon, B., and Kim, J. M. (2012) Polydiacetylenes: supramolecular smart materials with a structural hierarchy for sensing, imaging and display applications, Chem. Commun. 48, 2469-2485.

7. Barcena-Uribarri, I., Thein, M., Barbot, M., Sans-Serramitjana, E., Bonde, M., Mentele, R., Lottspeich, F., Bergstrom, S., and Benz, R. (2014) Study of the protein complex, pore diameter, and pore-forming activity of the Borrelia burgdorferi P13 porin, J. Biol. Chem. 289, 18614-18624.

8. Goulart, C. L., Bisch, P. M., von Kruger, W. M., and Homble, F. (2015) VCA1008: An Anion-Selective Porin of Vibrio Cholerae, Biochim. Biophys. Acta 1848, 680-687.

9. Maurya, S. R., and Mahalakshmi, R. (2015) N-helix and cysteines inter-regulate human mitochondrial VDAC-2 function and biochemistry, J. Biol. Chem., In press. DOI: $10.1074 /$ jbc.M1115.693978. 